Reconciling Changes in Wage Inequality With Changes in College Selectivity Using a Behavioral Model

Allier savoir et décision

CHRISTIAN BELZIL JÖRGEN HANSEN 


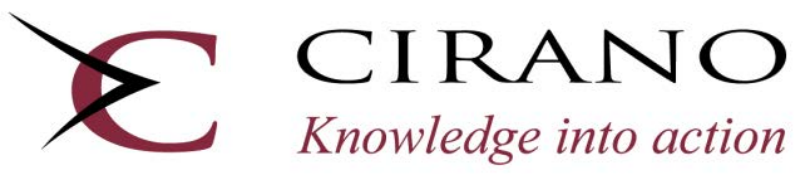

Center for Interuniversity Research and Analysis on Organizations

The purpose of the Working Papers is to disseminate the results of research conducted by CIRANO research members in order to solicit exchanges and comments. These reports are written in the style of scientific publications. The ideas and opinions expressed in these documents are solely those of the authors.

Les cahiers de la série scientifique visent à rendre accessibles les résultats des recherches effectuées par des chercheurs membres du CIRANO afin de susciter échanges et commentaires. Ces cahiers sont rédigés dans le style des publications scientifiques et n'engagent que leurs auteurs.

CIRANO is a private non-profit organization incorporated under the Quebec Companies Act. Its infrastructure and research activities are funded through fees paid by member organizations, an infrastructure grant from the government of Quebec, and grants and research mandates obtained by its research teams.

Le CIRANO est un organisme sans but lucratif constitué en vertu de la Loi des compagnies du Québec. Le financement de son infrastructure et de ses activités de recherche provient des cotisations de ses organisations-membres, d'une subvention d'infrastructure du gouvernement du Québec, de même que des subventions et mandats obtenus par ses équipes de recherche.

\section{CIRANO Partners - Les partenaires du CIRANO}

Corporate Partners - Partenaires corporatifs

Autorité des marchés financiers

Bank of Canada

Bell Canada

BMO Financial Group

Business Development Bank of Canada

Caisse de dépôt et placement du Québec

Desjardins Group

Énergir

Hydro-Québec

Innovation, Science and Economic Development Canada

Intact Financial Corporation

Manulife Canada

Ministère de l'Économie, de la Science et de l'Innovation

Ministère des finances du Québec

National Bank of Canada

Power Corporation of Canada

PSP Investments

Rio Tinto

Ville de Montréal

Academic Partners - Partenaires universitaires

Concordia University

École de technologie supérieure

École nationale d'administration publique

HEC Montréal

McGill University

National Institute for Scientific Research

Polytechnique Montréal

Université de Montréal

Université de Sherbrooke

Université du Québec

Université du Québec à Montréal

Université Laval

CIRANO collaborates with many centers and university research chairs; list available on its website. Le CIRANO collabore avec de nombreux centres et chaires de recherche universitaires dont on peut consulter la liste sur son site web.

(c) June 2020. Christian Belzil, Jörgen Hansen. All rights reserved. Tous droits réservés. Short sections may be quoted without explicit permission, if full credit, including (C) notice, is given to the source. Reproduction partielle permise avec citation du document source, incluant la notice (C).

The observations and viewpoints expressed in this publication are the sole responsibility of the authors; they do not necessarily represent the positions of CIRANO or its partners. Les idées et les opinions émises dans cette publication sont sous l'unique responsabilité des auteurs et ne représentent pas nécessairement les positions du CIRANO ou de ses partenaires. 


\title{
Reconciling Changes in Wage Inequality With Changes in College Selectivity Using a Behavioral Model *
}

\author{
Christian Belzil †, Jörgen Hansen *
}

\begin{abstract}
Résumé
We estimate a structural dynamic Roy model of education, labor supply and earnings on the 1979 and 1997 cohorts of males taken from the National Longitudinal Survey of Youth (NLSY) and evaluate to what extent changes in education and labor supply decisions across cohorts have been explained by changes in i) the college premium, ii) the utility of attending higher education, iii) grade progression standards, and iv) the value of non-market time. We quantify the evolution of the relative and absolute qualities of both college graduates and college attendants (associates). We find that it is impossible to rationalize changes in observed schooling decisions without appealing to a large increase in intrinsic taste for education, despite a doubling of the cost of college and its impact on debt-load. The population distribution of the college premium has shifted to the right, going from $50 \%$ to $58 \%$, while the premium of actual college graduates has shifted to the left, going from $72 \%$ to $54 \%$, thereby pointing toward a reduction of the relative quality of college graduates. The absolute quality (human capital) of college graduates has however remained stable. For college attendants (associates), both relative and absolute quality dropped. One implication of the relative attening of age earnings profiles is the removal of the negative effect of late college graduation on early life-cycle wages. Our estimates indicate it moved from a $4 \%$ penalty per year of delay to an insignificant quantity by the early 2000 's.
\end{abstract}

Keywords/Mots-clés: Wage Inequality, Educational Selectivity, Wage Distribution, College Premium, Dynamic Discrete Choice

JEL Codes/Codes JEL: I2, J1, J3

\footnotetext{
* We thank Peter Arcidiacono, Lance Lochner, Arnaud Maurel and Douglas Webber for comments and discussions. Financial support from Investissement d'Avenir (ANR-11-IDEX-0003/ Labex Ecodec/ANR-11-LABX-0047) and Social Sciences and Humanities Research Council of Canada (grant 435-2017-0129) are gratefully acknowledged. The usual disclaimer applies.

$\uparrow$ Paris Polytechnic Institute, CIRANO and IZA

* Concordia University, CIREQ, CIRANO and IZA
} 


\section{Introduction}

In recent decades, important changes in the US wage distribution and in educational outcomes have been observed. In particular, the well documented increase in cross-sectional wage inequality has been accompanied by a significant raise in the cost of college education. ${ }^{1}$ In parallel, average borrowing levels and student employment have both increased while education financing opportunities have also developed. Despite the raise in the cost of college, higher education enrollments have constantly increased and there is reasonable evidence that institutional changes in the college market has translated into enrollment increases at lower quality colleges. As a result, it is difficult to say to what extent the evolution of wage inequality between education groups is due to changes in returns as opposed to changes in composition (or educational selectivity). It is equally challenging to assess if the evolution of education inequality is itself due to changes in returns or simply due to changes in taste. Indeed, all these facts are practically impossible to articulate without a behavioral model and this is precisely our main objective to build a structure that can help reconciling all of them.

In this paper, we estimate a structural dynamic Roy model of education, labor supply and earnings on the 1979 and 1997 cohorts of males taken from the National Longitudinal Survey of Youth (NLSY). The model maps unobserved heterogeneity onto economic primitives; utilities of attending education, utilities of working while in school, utilities of full time and part-time employment, the skill production technology, grade progression standards and the value of non-market time. While the focus of our paper is not on education financing, we still want to capture the impact of changes in the cost of university on the time allocation decision during college. We therefore incorporate three main sources of education financing; labor supply, borrowing and parental transfers.

We estimate parameters that rationalize observed choices after conditioning on both the average increase in the net cost of higher education observed between the 1980's and the early 2000's and the related borrowing needs which depend on enrollment and labor supply decisions. We evaluate to what extent changes in education and labor supply decisions across cohorts

\footnotetext{
${ }^{1}$ In the next section, we discuss each of these important changes and relate them to some relevant background literature.
} 
have been affected by changes in each component of the model and use the model to quantify the evolution of educational selectivity and in particular the evolution of the relative and absolute qualities of both college graduates and college attendants (associates).

In the paper, we follow two distinct approaches that differ in terms of the specification of the skill production function. First, we estimate the same model separately on both cohorts. Without specific assumptions about how the skill (human capital) production function might have evolved, it is not possible to separate changes in human capital from changes in skill prices and therefore impossible to compare average human capital across cohorts. However, it is possible to quantify the evolution of the distribution of the college-high school premium and in particular to assess if the distance between the average college premium in the population and the college premium of actual college graduates (essentially a treatment effect for the treated) has moved across cohorts. We may therefore measure to what extent wages of more recent cohorts of college attendants or college graduates tend to diverge from (or converge to) population averages. These constitute our measure of the evolution of "relative quality".

In the second approach, we condition on results obtained for the earlier cohort and impose stationarity of the skill production function for each education group across cohorts. We can thereby separate movements in skill prices (reflecting institutional or technological changes) from movements in the human capital level of college graduates and college attendants (changes in composition) between the 1980's and the early 2000's. With these assumptions, we can measure the evolution of "absolute quality".

To estimate the model, we use data on school attendance, grade progression, hours worked while in school, hours worked beyond school completion and earnings from both cohorts of the NLSY. On top of this, we use net college cost data from the Integrated Postsecondary Education Data System (IPEDS) as well as borrowing data from the National Postsecondary Student Aid Survey (NPSAS), available for the 1980's and 2000's. Our estimation strategy was guided by the willingness to use the exact same model and identical sources of data for both cohorts so that identification of the same key parameters could be guaranteed. While the models estimated in Johnson (2012) and Keane and Wolpin (2001) are more complex, our approach also 
guarantees comparability across cohorts. ${ }^{2}$

The model allows for four distinct education groups; high school dropouts (11 years of schooling or less), high school graduates (12 years), college associates (between 13 and 15 years) and college graduates (16 years or more). Each type of schooling has its own wage function which depends on unobserved heterogeneity and on endogenous work experience (years of part-time and full-time employment) and wages are defined as the product of human capital and a skill price specific to each type of education. Our model is therefore capable of evaluating to what extent the flattening of US age earnings profiles may be robust to the allowance for endogeneity of schooling decisions and for changes in selectivity.

As our model dissociates school attendance decisions from grade progression by modeling the latter as a stochastic outcome depending on endogenous labor supply while in school, on grade attended and on individual unobserved heterogeneity, it accounts for the fact that total time needed to complete college is endogenous and may be used to study the evolution of the causal effect of later college graduation on early life-cycle wages.

At the outset, it should be clear that our analysis focuses on the early stage of the life-cycle only. There are many good reasons for doing so. First, and as is documented in Card and Lemieux (2001), the very high collegehigh school premium is found primarily among younger workers. In their comparison of the post-2000 and pre-2000 entry cohorts performed with the Outgoing Rotation Group (ORG) of the Current Population Survey, Beaudry, Green and Sand (2014) also restrict their analysis to the early phase of the life-cycle. Secondly, the 1997 cohort analyzed in the paper had to face the 2008 recession around age 29-30 and it is highly unlikely that a majority of those young individuals made educational and labor supply choices expecting such disruptive events. Third, focussing on the early phase of the life-cycle obviates the need to model explicit individual expectations about wages that would be realized in a distant future. For all these reasons, and in order to obtain symmetry across cohorts, we judge it desirable to limit our analysis to the early phases of the life-cycle for both the 1979 and the 1997 cohorts.

Finally, as our interest does not lie in counterfactual policy changes, our

\footnotetext{
${ }^{2}$ There are sources of data that are available in one cohort and not the other. For instance, parental wealth is documented in the 1997 cohort but not in the 1979 cohort (see Johnson, 2012). Keane and Wolpin (2001) use asset depletion to approximate parental transfers in their analysis of the 1979 cohort.
} 
model is set in partial equilibrium. It implicitly assumes that the earlier cohort knows the skill price prevailing over the early phase of the life-cycle (over the early 1980's) and makes schooling decisions based upon it. Similarly, we assume that the recent cohort is aware of the changes in skill prices that took place over the previous 20 year period (or lack thereof) and regards the current skill prices as the relevant ones when making decisions. ${ }^{3}$

The model is estimated by simulated maximum likelihood using choices and outcomes observed between age 16 and 28. To facilitate estimation, we follow Sullivan (2006) and implement an interpolation method in the spirit of Keane and Wolpin (1997) and which is adapted for models with Extreme Value utility shocks (Rust, 1987). Like all interpolation methods, it first requires to solve value functions at a limited subset of the state space and use these values within a regression to approximate value functions for the remaining elements of the state space.

\section{Main Results}

While some of the results reported in the paper are specific to each approach, some are common to both. We now summarize four main findings.

First, and foremost, it is impossible to rationalize changes in observed schooling decisions without appealing to an increase in intrinsic taste for education. This is true even if the total costs of college have practically doubled and borrowing levels have increased accordingly. While the magnitude of the increase varies with the specification, our estimates indicate that net consumption while in school (including non-monetary components of attending

\footnotetext{
${ }^{3}$ Our approach is different from that of Bowlus and Robinson (2012) who tackle a similar question using data on several cohorts of US labor force participants. Their analysis is based on identification of movements in skill prices and on the existence of "Flat Spots" in age earnings profiles. They use the Current Population Survey March files for 19642009 and find that skill price series of various education groups are highly correlated and exhibit a strong secular trend. They conclude that the rising college premium is more likely to be driven by relative quantity than relative price changes. More recently, Castro and Coen-Pirani (2016) have investigated to what extent a calibrated Ben-Porath model with ability heterogeneity can explain long-run changes in education in the US. They claim that about two thirds of the increase in college enrollments observed over the past century is due to an increase in skill prices but also report that their model imputes the stagnation in college enrollments to a decrease in ability, as measured by various achievement tests designed by the Congressional Budget office. Their model however ignores the role of unobserved heterogeneity which has been found the most important determinant of schooling attainments in the structural microeconometric literature, even after controlling for cognitive ability.
} 
college) have increased by $60 \%$ to $70 \%$ when assuming a stationary skill production function and have been multiplied by a factor of 2 to 4 (depending on hours worked while in school) when the model is estimated freely on both cohorts.

A second major finding is the decline in relative quality of college graduates but stability of its absolute quality. The drop in relative quality may either be illustrated by the tendency of the population average college premium and the realized college premium to converge to a similar value, or simply by comparing expected wages of actual college graduates with mean wages in a college graduate job for the population. Our estimates indicate that the difference between the average college premium in the population and the realized college premium has been divided by 4 between the 1980 's and the early 2000's. While the realized college premium moved from $72 \%$ in the 1979 cohort to $54 \%$ in the 1997 cohort, the population average premium moved from $50 \%$ to $58 \%$. In other words, while the population average college-high school premium increased modestly, the realized college premium dropped substantially. Overall, this indicates that between 1980 and the early 2000's, the sub-population of college graduates have become gradually more representative of the population, thereby pointing to a decline in the relative quality of college graduates.

The decline in relative quality of college graduates is also clear when comparing mean wages (as opposed to returns). In the 1979 cohort, there was strong positive selection characterizing college graduates, as they earned $8 \%$ more than the population average in a college job. By the early 2000, college graduates earned only $2 \%$ more than the population average and positive selection prevailing in the early 1980's had almost entirely vanished. However, our estimates obtained from the restricted version of the model indicate that the average level of human capital of college graduates in the early 2000's is similar to college graduates of the 1980's and that their skill price has not changed. The absolute quality of college graduates has therefore remained constant.

A third finding is the decline in both relative and absolute quality of college associates. In the early 1980's, the average wage of college associates (in a college associate job) was slightly above the population average as the differential was about $3 \%$ and therefore pointed toward the existence of positive selection among college associates. In the 1997 cohort, the ordering was reversed and the sub-population of college associates was earning $5 \%$ less 
than the population average. Positive selection was transformed into negative selection. When distinguishing between change in skill prices and changes in human capital (something feasible only when restricting the skill production functions to be stationary), we find that the average human capital level of college associates has depreciated by $9 \%$ while their skill price has increased by $20 \%$ and therefore concluded in favor of a decrease in absolute quality of college associates.

Another interesting finding, which was disclosed by the unrestricted model (and imposed on the restricted one) is the changing structure of the college premium. In the early 1980's, college graduates experienced much larger wage gains in the early phase of the life-cycle due to a 6 percentage points difference in returns to experience compared with high school graduates. In the 1997 cohort, age earnings profiles have flattened and the college-high school differential in returns to full-time experience has been reduced by half while the college-high school premium seems to be located at entrance in the market. One implication of the relative flattening of age earnings profiles, along with changes in labor supply decisions, is the practical elimination of the negative effect of late college graduation on early life-cycle wages. Our estimates indicate that it moved from a $4 \%$ penalty per year of delay to an insignificant quantity by the early 2000's.

The remaining sections of the paper are organized as follows. In Section 2, we discuss arguments motivating our research and review the relevant literature. In Section 3, we summarize some of the most striking differences between the 1979 and the 1997 cohorts of the NLSY. Section 4 is devoted to the presentation of the structural model. In the following section, we discuss the main results obtained when estimating the model separately on each cohort. In Section 6, we present those obtained from an estimation procedure that forces the skill production functions to be stationary across cohorts. A brief summary of the main findings and some concluding remarks are found in Section 7. 


\section{Motivation and Background Literature}

The increase in wage inequality taking place over the last decades is one of the most celebrated stylized facts about the US labor market. Inequality has not only increased between education groups but also within groups. The literature concerned with the evolution of wage inequality is vast and remains descriptive for the most part. A first set of papers have concentrated on studying changes in wage distributions that took place since the late 1970's and until the late 1990's. This segment of the literature, surveyed in Card and Lemieux (2001) and Autor, Katz and Kearney (2008), has pointed out the importance of the increase in the college-high school premium (inequality between groups) as well as an overall increase in dispersion of the wage distribution in the US. While there is no agreement about the main causes behind these changes, their magnitude does not seem contentious. These changes have been reported in numerous papers and are widely recognized.

A more recent literature focussing on the evolution of the wage distribution since the early 2000's has been less consensual. Recent papers by Beaudry, Green and Sand (2012, 2014), Valetta (2016) and Ashworth, Hotz, Maurel and Ransom (2020) report a drop in the college premium when comparing college graduates in the early 2000's with those graduating in the 1980's. Others, including Deming (2017), report evidence favoring a sustained increase in the college premium.

Comparison across studies is however difficult to achieve. First, some authors have used the PSID while others focussed on the NLSY. Second, different authors use different specifications of the wage equation. To illustrate this, note that Ashworth et al. (2020), who compare the 1979 and 1997 cohorts of the NLSY, estimate returns to schooling after conditioning on a cognitive and a non-cognitive factor and allow for endogenous schooling and work decisions. Their approach, although less structural than our's, is the one that is the closest to the current paper. Others, such as Deming (2017) and Castex and Dechter (2014) ignore work experience. On top of this, those using the NLSY may not always be using the exact same samples. For instance, Ashworth et al. (2020) use the younger individuals of the 1979 cohort, while Deming uses a larger cohort. Finally, and as documented in Belzil, Hansen and Liu (2017), both OLS and IV estimates of the returns to schooling are highly dependent on the age at which wages are measured.

In light of these major changes in the wage distribution, Scott-Clayton 
(2012), Bound, Lovenheim and Turner (2012), Murphy and Topel (2016) and Ashworth et al. (2020), have documented a parallel increase in college enrollments as well as a raise in time needed to graduate from college induced by a clear increase in work experience during college.

The evolution of the direct costs of higher education is more difficult to assess since published tuition fees over-estimate the actual cost paid by students by a wide margin and because parental transfers (which may take multiple forms) are difficult to measure. Data from the College Board and the US Department of Education indicate that, for the period going from 1980 to 2000, both the net cost of education and the average borrowing level (conditional on borrowing) have doubled. ${ }^{4}$

Another key evolution of the US labor market has been the gradual "flattening" of age earnings profiles. Jeong, Kim, and Manovskii (2015), and Kambourov and Manovskii (2009) point out that the average earnings growth rates of various cohorts have been gradually decreasing. Kong, Ravikumar and Vandenbroucke (2017) report that age-earnings profiles of high school graduates in the 1980 cohort (those turning 18 in 1980) were about $50 \%$ flatter than high school graduates in the 1940 cohort. Similarly, age earnings profiles of college educated workers in the 1980 cohort were $27 \%$ flatter than their 1940 counterparts.

In parallel to this, one important fact that has attracted much less attention is the evolution of educational selectivity. Hoxby (2009) points out a certain number of institutional changes in the college market that contributed to a decrease in selectivity between the early 1980's and the early 2000's. In particular, she shows that enrollments have increased mostly at lower quality colleges. Indeed, Babcock and Marks (2011) who analyze grade inflation and study times in the US, find that hours spent studying have fallen dramatically while course grades have increased substantially over a long period.

The statistical implications of those institutional changes are however difficult to measure. The incidence of changes in educational selectivity has also

\footnotetext{
${ }^{4}$ Over a longer period, Abel and Deitz (2014) conclude that between 1970 and 2013, net tuition for a 4-year college degree tripled, going from $\$ 4,600$ to $\$ 15,500$ (in 2013 US dollars). It is important to note that the "sticker price" posted by colleges ignores several types of financial aid received by students, including grants from the institution itself. Over the same period, the sticker price also tripled. However, and as pointed out in Dynarski and Scott-Clayton (2016), the emergence of a multiplicity of higher education financial aid programs has transalted into a decrease in net prices between 2005 and 2011.
} 
attracted attention among those involved in education policies. According to the National Center for Education statistics, the yearly flow of individuals graduating with a Bachelor's degree has fluctuated between 1.5 and 3.0 million per year between 2005 and 2018. These numbers are far in excess of those for the early 1980's. ${ }^{5}$

All in all, the empirical micro-econometric literature on wage inequality remains highly descriptive. With the exception of Ashworth et al. (2020), it is probably fair to say that neither the importance nor the sources of changes in educational selectivity have been evaluated within econometric behavioral models.

The structural nature of our approach drives many resemblances with papers that have estimated behavioral models of schooling decisions. A set of papers modeling education within a partial equilibrium framework has focussed on issues such as occupation choices (Keane and Wolpin, 1997, and Todd and Zhang, 2019), the decision to drop out of high school (Eckstein and Wolpin, 1999), evaluating the impact of borrowing constraints on education (Keane and Wolpin, 2001) or measuring the ability bias (Belzil and Hansen, 2002). In all of those papers (except for Todd and Zhang, 2019), inference is based on a single cohort taken from the NLSY79. ${ }^{6}$

A relatively smaller number of papers have modeled schooling and occupational choices within an equilibrium framework. For instance, Heckman, Lochner and Taber (1998) and Lee and Wolpin (2010) estimated equilibrium models of the labor market using aggregate production technologies so to identify the major causes explaining changes in the wage distribution and in employment patterns. Gemici and Wiswall (2014) investigated movements in college major specific skill prices (especially the sciences) and document the importance of changes in schooling cost and gender specific changes in household production needed to explain changes in major choices. ${ }^{7}$

It is important to note that while all of these papers allow for endogenous schooling decisions, none of them examine the role of changes in educational selectivity. Indeed, it should be noted that despite the impressive number of papers documenting the magnitude of the increase in the college-high school

\footnotetext{
${ }^{5}$ Source: 120 years of American Education: A Statistical Portrait, National Center for Education Statistics, 1993.

${ }^{6}$ Belzil (2006) surveys the structural schooling literature.

${ }^{7}$ Gemici and Wiswall (2014) do not use aggregate production functions to identify skill prices. They also ignore change in selectivity driven by unobserved heterogeneity.
} 
premium and the raise in wage dispersion, the co-movements between educational attainments and the wage distribution have only recently attracted some attention.

In a recent paper, Belzil and Hansen (2020) examined the evolution of the effects of parental income and AFQT scores on college participation and graduation using a reduced-form dynamic discrete choice model using both the NLSY79 and the NLSY97. They show that, contrary to conventional wisdom, the effects of family income on college participation and college graduation have completely vanished and that the effects of AFQT scores have been divided by 2 . However, unobserved heterogeneity has become more important thereby indicating that classical educational selectivity based partly on cognitive abilities and/or family income is being gradually replaced by a different form of selectivity based on unmeasured abilities, costs or preferences.

Changes in dynamic selection have also been analyzed in Carneiro and Lee (2011) and in Ashworth et al. (2020). Ashworth et al (2020) report that after taking into account changes in selectivity and changes in labor supply while in school, the returns to schooling have decreased since the mid 1980's and the average level of cognitive and non-cognitive skills of college graduates have also decreased. Changes in education selection have also been raised as one potential reason for the observed "flattening" of age earnings profiles (Kong, Ravikumar and Vandenbroucke, 2017). Based on a standard Ben-Porath model of human capital accumulation on-the-job, the authors calibrate a model in which recent cohorts facing higher skill prices are induced to raise their investment in college human capital either at the intensive or extensive margin. As a consequence, the average abilities in recent cohorts of both high school graduates and college graduates have decreased thereby contributing to the flattening of age earnings profiles.

\section{The 1979 and the 1997 Cohorts of the NLSY}

Our analysis is based on data from two cohorts of the National Longitudinal Survey of Youth, NLSY79 and NLSY97. The NLSY79 is a nationally representative sample of 12,686 young men and women who were 14-22 years old when they were first surveyed in 1979 while the NLSY97 consists of a nationally representative sample of 8,984 youths who were 12-16 years old 
as of late December 1996. For both NLSY cohorts, there are detailed information on family background and income as well as on individual scholastic ability (measured by AFQT scores). Interviews are ongoing for both cohorts and conducted on a annual or biannual basis. The NLSY is one of the most commonly used data set in the US. While the surveys have been constructed to preserve symmetry across cohorts, attrition appears to be slightly more important in the 1997 cohort. $^{8}$

In our sample, an individual must report to be attending school both in September and in January in order to be classified as enrolled in school. In parallel, we use information on highest grade completed when the school year starts in order to obtain the dynamics of grade progression. This allows us to distinguish between school enrollment and grade progression (a key feature of our model).

To incorporate information about labor supply while in school, we define the academic year as the 9 month period going from September to late May and then use the weekly employment histories in order to obtain average weekly hours worked during that period. These pieces of information therefore allow us to divide the population of individuals attending school into various sub-groups that differ according to their labor supply intensities during school. For those who are not in school, the intensive labor supply margin is identified using the entire year as a reference. A final requirement is therefore that hours of worked (either during school year or not) be observed so that we can construct the entire schooling enrollment-labor supply histories of each individual.

The wage information was obtained from self-reported pay at the main job and, unless reported as an hourly rate, converted to a rate per hour. Wages are adjusted for inflation using CPI and expressed in dollars of year 1997. Summary statistics are found in appendix.

After these exclusions, we obtain samples of 1,294 individuals for the 1979 cohort, and 2,069 individuals for the 1997 cohort. A detailed description of exclusions is provided in appendix. For all those individuals, we measure hourly wages

\footnotetext{
${ }^{8}$ An in-depth comparison between the 79 and 97 cohorts is found in Nielsen (2015).
} 


\subsection{The Allocation of Time between School and Work}

As noted in other papers, the fraction of young males attending school has increased at most ages and individuals tend to be enrolled over longer periods. In Table 1, we report the frequency distributions of those enrolled by labor supply status. Although a full table reporting all frequencies at all ages is found in appendix, we focus on age 20 , at which potential college graduates are usually enrolled, and as well as age 23 and 28 .

At all ages, the total percentage of those who are in school in the 1997 cohort $(8.1 \%$ at age $28,15.7 \%$ at $23,35 \%$ at 20 ) exceeds that of the 1979 cohort $(4.7 \%$ at $28,11.5 \%$ at 23 and $32 \%$ at age 20$)$. This is therefore coherent with the overall increase in college enrollments pointed out in several papers.

One interesting feature is the relatively stable fraction of the population that is enrolled without working, or working part-time, at age 20. The frequency of school with no work remains about $11 \%$ even if the cost of higher education has doubled and is coherent with the overall increase in net borrowings that was mentioned earlier. The proportion of individuals enrolled and working part-time has also remained stable, but the proportion of young individuals enrolled while working full-time has increased significantly from $4.8 \%$ to $7.2 \%$.

At age 23, the proportions of individuals enrolled in school has increased at all labor supply modalities between the 1980's and the early 2000's. We also note that in the 1979 cohort, virtually everyone enrolled in school at age 28 reports also working full-time. This is not the case, in the 1997 cohort, in which about $40 \%$ of those enrolled in school at age 28 , are either not working or working part-time. This is a good illustration of the increasing tendency in taking more time to graduate from college. ${ }^{9}$

Differences in education outcomes, enrollment rates and experience are also perceptible upon examination of Table 2. Despite relatively stable graduation rates (23.8\% in the 1979 cohort and $24.0 \%$ in the 1997 cohort), the average number of enrollment periods has increased from 3.4 years to 4.2 years per individual. The number of years of full-time experience by age 25 has decreased from 4.0 to 3.2 but at the same, full-time experience during college has increased from 0.41 to 0.65 , indicating a clear increase in the incidence of employment while enrolled.

\footnotetext{
${ }^{9}$ This was noted in Bound, Lovenheim and Turner (2012).
} 


\subsection{The Evolution of Wage Inequality}

In Table 3A, we report OLS estimates obtained from log wage regressions on education group indicators (high school graduates being the reference) and on various measures of work experience. Aside from separating full-time and part-time work experience, we also incorporate a standardized version of individual AFQT scores as it is usually considered a good approximation of individual cognitive abilities.

We focus on the college-high school premium as it is one of the most common measure of the evolution of wage inequality. First, we note a general tendency for the college skill premium to be highly sensitive to the inclusion of experience. For instance, in the 1979 cohort, ignoring experience discloses a college premium of $32 \%$ while it raises to $42 \%$ when experience is accounted for. When AFQT score is included, the premium drops to $37 \%$.

In the 1997 cohort, the college premium also raises from $30 \%$ to $38 \%$ when experience is incorporated, but including AFQT scores has a much smaller impact than in the 1979 cohort as the premium drops to $37 \%$.

One clear feature from our data is the evidence against a raise in the college-high school premium. For any given regression specification, the premium either drops or remains constant. For instance, when both experience and AFQT scores are included, the 1979 and 1997 college premia are both equal to $37 \%$.

This does not mean that OLS estimates do not disclose increase in inequality between 1979 and 1997. In particular, OLS estimates obtained when controlling for AFQT and experience indicate that the high school graduate-high school drop-out difference has increased. In the 1979 cohort, the premium was inexistent while it increased to $6 \%$ in the 1997 cohort. This obviously means that college-high school drop out wage differential has also increased by about $6 \%$ in the early 2000's.

Our sample data disclose a difference between early life-cycle returns to part-time experience and full-time experience. Both with and without AFQT scores, returns to full-time experience have slightly increased, while return to part-time experience have been divided by 2 or 3 . Finally, and as noted in Castex and Dechter (2014), the effect of AFQT scores has been substantially reduced, going from 0.5 to 0.1 .

In Table 3B, we report OLS estimates of the returns to full-time experi-

ence, part-time experience and the full-time wage premium for each education 
group. Overall, the parameter estimates indicate that early life-cycle wage profiles of college graduates have flattened by more than 2 percentage points and those of college attendants by more than 0.7 percentage point. On the other hand, the returns to experience of both high school drop-outs and high school graduates have been stable.

Table 1

Differences in labor supply while in school between the 1979 and the 1997 Cohorts

\begin{tabular}{|l|l|l|}
\hline & 1979 Cohort & 1997 Cohort \\
\hline \hline & Percentage & Percentage \\
\hline \hline Age 20 & & \\
\hline in school no work & $10.7 \%$ & $11.0 \%$ \\
\hline in school-part-time work & $16.6 \%$ & $17.0 \%$ \\
\hline in school-full-time work & $4.8 \%$ & $7.2 \%$ \\
\hline Total & $32 \%$ & $35 \%$ \\
\hline & & \\
\hline Age 23 & & \\
\hline in school no work & $2.8 \%$ & $5.1 \%$ \\
\hline in school-part-time work & $3.8 \%$ & $5.1 \%$ \\
\hline in school-full-time work & $4.9 \%$ & $5.5 \%$ \\
\hline Total & $11.5 \%$ & $15.7 \%$ \\
\hline & & \\
\hline Age 28 & & \\
\hline in school no work & $0.01 \%$ & $1.9 \%$ \\
\hline in school-part-time work & $\approx 0 \%$ & $1.0 \%$ \\
\hline in school-full-time work & $4.7 \%$ & $5.1 \%$ \\
\hline Total & $4.7 \%$ & $8.1 \%$ \\
\hline
\end{tabular}


Table 2

Differences in Education and Experience between the 1979 and the 1997 Cohorts

\begin{tabular}{|l|l|l|}
\hline & $\mathbf{1 9 7 9}$ Cohort & 1997 Cohort \\
\hline \hline Variables & Percentage & Percentage \\
\hline \hline & & \\
\hline High School Drop Outs (age 28) & $17.4 \%$ & $23.5 \%$ \\
\hline High School graduates (age 28) & $38.6 \%$ & $27.0 \%$ \\
\hline College Associates (age 28) & $20.2 \%$ & $25.6 \%$ \\
\hline College graduates (age 28) & $23.8 \%$ & $24.0 \%$ \\
\hline & & \\
\hline & Years & Years \\
\hline Enrollment in College & 3.44 & 4.20 \\
\hline full-time experience (age 25) & 4.03 & 3.25 \\
\hline part-time experience (age 25) & 2.16 & 2.14 \\
\hline Full-time experience during college (age 25) & 0.41 & 0.65 \\
\hline part-time experience during college (age 25) & 1.99 & 1.82 \\
\hline & & \\
\hline
\end{tabular}

Note: Education outcomes are defined from reported highest grade completed at age 25. Those who have obtained a GED are classified as drop-outs. 
Table 3A

Documenting Changes in the Wage Distribution of the 1979 and the 1997 Cohorts

\begin{tabular}{|l|c|c|c|c|c|c|}
\hline & \multicolumn{6}{|c|}{ Pooled OLS Estimates } \\
\hline \hline Dependent Variable & log wages & log wages & log wages & log wages & log wages & log wages \\
\hline \hline & $(1)$ & $(2)$ & $(3)$ & $(4)$ & $(5)$ & $(6)$ \\
\hline \hline & 1979 & 1997 & 1979 & 1997 & 1979 & 1997 \\
\hline intercept & & & & & & \\
\hline & $2.4478^{* *}$ & $2.4160^{* *}$ & $2.1509^{* *}$ & $2.1812^{* *}$ & $2.1233^{* *}$ & $2.1709^{* *}$ \\
\hline Education & & & & & & \\
\hline HS Drop-out & $-0.0760^{* *}$ & $-0.0977^{* *}$ & $-0.0206^{* *}$ & $-0.0674^{* *}$ & 0.0091 & $-0.0625^{* *}$ \\
\hline HS Graduates & - & - & - & - & - & - \\
\hline Associates & $0.0380^{* *}$ & $0.0680^{* *}$ & $0.1559^{* *}$ & $0.1418^{* *}$ & $0.1321^{* *}$ & $0.1362^{* *}$ \\
\hline College Graduates & $0.3156^{* *}$ & $0.2967^{* *}$ & $0.4253^{* *}$ & $0.3776^{* *}$ & $0.3752^{* *}$ & $0.3657^{* *}$ \\
\hline & & & & & & \\
\hline Exper (full time) & - & - & $0.0784^{* *}$ & $0.0855^{* *}$ & $0.0804^{* *}$ & $0.0860^{* *}$ \\
\hline & & & & & & \\
\hline Exper. (part-time) & - & - & $0.0256^{* *}$ & $0.0106^{* *}$ & $0.0324^{* *}$ & $0.0114^{* *}$ \\
\hline & & & & & & \\
\hline AFQT & - & - & - & - & $0.0549^{* *}$ & $0.0140^{* *}$ \\
\hline & & & & & & \\
\hline
\end{tabular}

Note: The estimates for education groups are in reference to high school graduates (the reference group).

Note: Parameter estimates with $* *$ are significant at $1 \%$.

Note: AFQT scores are standardized 
Table 3B

Documenting Changes in Returns to Experience for the 1979 and the 1997 Cohorts

\begin{tabular}{|l|c|c|c|}
\hline & \multicolumn{3}{|c|}{ Pooled OLS Estimates } \\
& \multicolumn{2}{|c|}{ Regressors } \\
\hline \hline & Part-Time Exper & Full-Time Exper. & Full-time job \\
\hline 1979 & & & \\
\hline HS Drop-out (log wages) & $0.021^{* *}$ & $0.068^{* *}$ & $0.027^{* *}$ \\
\hline HS Graduates (log wages) & $0.010^{* *}$ & $0.078^{* *}$ & $0.097^{* *}$ \\
\hline Associates (log wages) & $0.035^{* *}$ & $0.074^{* *}$ & 0.032 \\
\hline College Graduates (log wages) & $0.038^{* *}$ & $0.124^{* *}$ & $0.107^{* *}$ \\
\hline & & & \\
\hline 1997 & & & $0.078^{* *}$ \\
\hline HS Drop-out (log wages) & $0.028^{* *}$ & $0.070^{* *}$ & $0.055^{* *}$ \\
\hline HS Graduates (log wages) & 0.006 & $0.080^{* *}$ & $0.097^{* *}$ \\
\hline Associates (log wages) & $0.037^{* *}$ & $0.067^{* *}$ & $0.146^{* *}$ \\
\hline College Graduates (log wages) & -0.026 & $0.102^{* *}$ & \\
\hline
\end{tabular}

Note: Parameter estimates with ${ }^{* *}$ are significant at $1 \%$. 


\section{The Model}

Because the structure of the model that we estimate is identical across cohorts, the presentation does not incorporate any reference to a specific cohort. We model choices from age 16 until age 28 only and define the academic year as the 9-month period going from September to May. To be classified as a part-time worker (whether also enrolled in school or not), an individual must work between 10 to 30 hours per week for the majority of that period. To be classified as full-time, the individual must have worked at least 31 hours for the majority of the period. Those who report working less than 10 hours are grouped with those enrolled in school with no work.

To allow the total time needed to complete college to be endogenous, we separate school enrollment from grade transition and model grade increment as a stochastic binary outcome that depends on current grade attainment (whether in high school or post-high school), on contemporaneous hours worked and on heterogeneity. Individuals who are not in school are classified in one the following three categories: part-time work, full-time work or home time. The classification used for part-time and full-time work is the same as the classification used for work while in school except that the reference period is the full year.

In total, individuals can move between 6 distinct states: school and no work $(s)$, school and part-time work $(s p)$, school and full-time work $(s f)$, full-time work $(f)$, part-time work $(p)$ and non-market production $(\mathrm{nm})$.

While the focus of our paper is not on education financing, we still want to capture the impact of changes in the cost of university on the time allocation decision during college. Because our model is a discrete choice model (and because it is impossible to know the explicit net amount that was borrowed by a given individual), we assume a representative borrowing level which depends on individual choices about enrollment and labor supply combinations, and we tie these amounts to data on cost of college obtained from official US

statistics. In turn, borrowing while in school translates into subsequent debtload and therefore affects subsequent repayments.

We consider 3 different elements determining consumption while in school (college). Those are loans (denoted $L$ ), individual own contributions generated from past employment (denoted $I$ ) and a residual component representing any sort of transfers (parental or other).

According to the National Postsecondary Student Aid Survey (NPSAS), 
the average borrowing level (in $\$ 2000$ ) was about $\$ 9605$ for the early 1980's and $\$ 15,011$ for the early 2000 's. However, those numbers are conditional on borrowing and do not allow to separate those who have completed college from those who have not. This means that it is difficult to obtain a reliable measure per enrollment year. ${ }^{10}$ Instead of using data on borrowing, we make use of college cost data coming from the Integrated Postsecondary Education Data System (IPEDS) available for the 1980's and 2000's. The costs reported by IPEDS incorporate net tuition, fee, room and board, and constitute the most standard method to measure what students pay for college. For the early 1980's, the average net cost (in year 2000 dollars) was about $\$ 3,648$ per year of college. For the early 2000's, the estimate is about $\$ 7,042$ per year and indicates that college costs have doubled over this 20 year period. ${ }^{11}$

To obtain identification of the net amount of consumption while in school, we impose a relationship between borrowing and enrollment-labor supply combinations. As a general rule, we assume that the cost of college may be covered by one of the following 3 options, borrowing, contemporaneous labor supply or by interrupting school in order to work and cover subsequent college costs. For instance, those attending college and are not working, will either need to borrow the full cost of college, or use previous employment (if they have interrupted school to work) to carry over an amount equivalent to tuition. Similarly, those who work part-time while in school need to borrow only half of it or use last period gains. Finally, those who work full-time are assumed not to borrow as we assume that their contemporaneous gains are sufficient to cover college costs. These assumptions essentially imply that individuals financing education by work and loans may have a similar consumption level, but that those who borrow build up future debt-load which reduces post-education wages. Details about debt repayment are provided below. ${ }^{12}$

\footnotetext{
${ }^{10}$ NPSAS (https://nces.ed.gov/surveys/npsas/) is a cross-sectional complex survey with a 2-stage sampling design. Institutions are sampled first, then students are selected from the sampled institutions' enrollment lists. The survey is designed to be nationally representative of students attending postsecondary institutions during an academic year.

${ }^{11}$ Those numbers represent an average between private and public institutions.

${ }^{12}$ One reason for using data outside the NLSY is that the NLSY79 and the NLSY97 do not contain the same information and therefore cannot be treated symetrically. A second reason is that individual choices are likely to depend on unobserved parental transfers (either in-kind or financial) which are practically unobserved. So for these reasons, and instead of introducing data subject to high measurement error, we rely on data provided
} 
Finally, the skill-production function is allowed to differ according to educational outcomes as in a Roy model. We assume the existence of a wage equation for each specific group; high school drop-outs, high school graduates, college associates and college graduates. The wage is interpreted as the product of a specific skill price per unit of human capital times the human capital level which depends itself on accumulated full-time, parttime experience and individual heterogeneity. Our specification of the skill production function is therefore coherent with the treatment effect literature in which the returns to schooling are heterogeneous and may be justified by the different natures of jobs accessible to each education group. Our modeling assumption therefore treats each education group as a specific skill. To capture the fact that wages of full-time workers may be higher than parttime wages or higher than wages paid while in school, we also allow wages to depend on a full-time work indicator.

We now present the notation used for each component of the model.

\section{Choices}

The variable $d_{t, s}$ is equal to 1 when an individual is in school at beginning of year $t$, and works 9 hours or less per week $\left(d_{t, s}=0\right.$ if not), $d_{t, s p}$ is equal to 1 when the individual is in school and works between 10 and 30 hours per week $\left(d_{t, s p}=0\right.$ if not), $d_{t, s f}$ is equal to 1 when the individual is in school and works more than 30 hours per week $\left(d_{t, s f}=0\right.$ if not), $d_{t, n m}$ is equal to 1 when the individual works 9 hours or less per week or involves in non-market activities $\left(d_{t, n m}=0\right.$ if not), $d_{t, p}$ is equal to 1 when the individual works between 10 hours and 30 hours per week $\left(d_{t, p}=0\right.$ if not), and finally $d_{t, f}$ is equal to 1 when the individual works more than 30 hours per week $\left(d_{t f}=0\right.$ if not).

\section{Borrowing and Debt}

When $d_{t, s}=1$, the amount of borrowing $\left(L_{t}^{s}\right)$ and the individual contribution $\left(I_{t}\right)$ are given by the following:

$$
\begin{aligned}
L_{t}^{s} & =T \cdot\left(1-\left(d_{t-1, p}+d_{t-1, f}\right)\right)+0.5 \cdot T \cdot d_{t-1, p} \\
I_{t} & =T \cdot d_{t-1, f}+0.5 \cdot T \cdot d_{t-1, p}
\end{aligned}
$$

by official statistical agencies and impute average amount of borrowing conditional on labor force status while in higher education. This is what allows us to estimate the level of consumption while in school. 
where $T$ denotes the yearly cost of college. This implies that full-time students who did not interrupt in the previous period need to borrow $T$ and that those who interrupted to work part-time in the previous period need to borrow half of $T$. For those who interrupted to work full-time, $L_{t}^{s}=0$.

When estimating the model, we set $T$ to its per-hour equivalent by dividing the total yearly cost by 2000 .

When $d_{t, s p}=1$, the amount of borrowing $\left(L_{t}^{s p}\right)$ is given by the following

$$
L_{t}^{s p}=0.5 \cdot T \cdot\left(1-\left(d_{t-1, p}+d_{t-1, f}\right)\right)
$$

When $d_{t, s f}=1$, there is no borrowing. For both $d_{t, s p}=1$ and $d_{t, s f}=1$, the individual contributions are given by the equation above.

\section{Utility of Attending Education}

We assume that the per-period utility function, which takes a logarithmic form, depends on the sum of good consumption and on non-pecuniary amenities. The utility of attending school full-time (with no work) for individual $i$ at time $t$ is denoted $U_{i t}^{s}$, while the utility of attending school and working part-time and full-time are denoted $U_{i t}^{s p}$ and $U_{i t}^{s f}$, respectively. ${ }^{13}$ They are defined as follows:

$$
\begin{aligned}
U_{i t}^{s} & =\bar{U}_{i t}^{s}+\varepsilon_{i t}^{s} \\
U_{i t}^{s p} & =\bar{U}_{i t}^{s p}+\varepsilon_{i t}^{s p} \\
U_{i t}^{s f} & =\bar{U}_{i t}^{s f}+\varepsilon_{i t}^{s f}
\end{aligned}
$$

where $\varepsilon_{i t}^{s}, \varepsilon_{i t}^{s p}$, and $\varepsilon_{i t}^{s f}$ are idiosyncratic stochastic shocks and where $\bar{U}_{i t}^{s}, \bar{U}_{i t}^{s p}$, and $\bar{U}_{i t}^{s f}$ are defined as follows

$$
\bar{U}_{i t}^{s}=\ln \left\{c_{i t}^{s}\right\}, \bar{U}_{i t}^{s p}=\ln \left\{c_{i t}^{s p}\right\}, \bar{U}_{i t}^{s f}=\ln \left\{c_{i t}^{s f}\right\}
$$

The terms $c_{i t}^{s}, c_{i t}^{s p}$ and $c_{i t}^{s f}$ are composite notions of total consumption incorporating both financial and non-pecuniary values of attending higher education. They are defined as follows;

\footnotetext{
${ }^{13}$ As far as we know, Eckstein and Wolpin (1999) were the first to model structurally the joint decision between attending school and work. Their paper focusses on high school enrollment.
} 


$$
\begin{aligned}
& c_{i t}^{s}=\alpha_{0}^{s}+\left(L_{t}^{s}+I_{t}(.)-T\right) \cdot 1\left(12 \leq G_{i t}\right)+\alpha_{1 i}^{s} \cdot 1\left(12 \leq G_{i t}\right)+\alpha_{2}^{s} \cdot 1\left(14 \leq G_{i t}\right) \\
& c_{i t}^{s p}=\alpha_{0}^{s p}+\left(L^{s p}+I_{t}(.)-T\right) \cdot 1\left(12 \leq G_{i t}\right)+\alpha_{3}^{s p} \cdot W_{i t}+\alpha_{1 i}^{s p} \cdot 1\left(12 \leq G_{i t}\right)+\alpha_{2}^{s p} \cdot 1\left(14 \leq G_{i t}\right) \\
& c_{i t}^{s f}=\alpha_{0}^{s f}+\left(I_{i}(.)-T\right) \cdot 1\left(12 \leq G_{i t}\right)+\alpha_{3}^{s f} \cdot W_{i t}+\alpha_{1 i}^{s f} \cdot 1\left(12 \leq G_{i t}\right)+\alpha_{2}^{s f} \cdot 1\left(14 \leq G_{i t}\right)
\end{aligned}
$$

and where $1($.$) is the indicator function.$

To obtain identification, the parameters $\alpha_{3}^{s p}$ and $\alpha_{3}^{s f}$, which capture potential additional consumption induced by working full-time or part-time, need to be normalized. We set the consumption level associated to full-time work to the per-hour wage rate equivalent, and normalize $\alpha_{3}^{s f}$ to 1 and $\alpha_{3}^{s p}$ to 0.5 . We interpret the intercept terms $\alpha_{0}^{s}, \alpha_{0}^{s p}$ and $\alpha_{0}^{s f}$, which are treated as free parameters, as quantities measuring minimum consumption level provided by the parents. ${ }^{14}$

The parameters $\alpha_{1 i}^{s}, \alpha_{1 i}^{s p}, \alpha_{1 i}^{s f}$ play the role of individual differences in the valuation of post-secondary education which may either come from heterogeneity in the non-pecuniary valuation of college attendance or from heterogeneity in consumption transfers. While both interpretations are admissible, and because they enter the utility function additively with respect to parttime and full-time wages, they are automatically expressed in dollar value (on a per-hour equivalence). Finally, the parameters $\alpha_{2}^{s}, \alpha_{2}^{s p}, \alpha_{2}^{s f}$ capture the variation in the utility of attending school when reaching grade 14 and beyond.

\section{The Utility of Working}

We define the utility of working full-time, denoted $U_{i t}^{f}$, and the utility of working part-time, denoted $U_{i t}^{p}$, in the same spirit as we did for work while in school. That is the per-period utility is the sum of a component measuring consumption and another one capturing the utility (or disutility.) of working longer hours.

To incorporate the implications of education financing on post-college wages, we assume a 10 years repayment stream at the student loan interest rate prevailing over the early 1980's and early 2000's. To obtain the

\footnotetext{
${ }^{14}$ This specification implies that we assume these minimum transfers to be the same if attending high school or college.
} 
repayment schedule, we approximate the debt-load by imputing an average borrowing level depending on the yearly status of the student and compute the repayment stream over 10 years at a specific interest rate using standard amortized loan expressions.

To construct the repayment schedule, we define the accumulated debt load $(D L)$ when entering period $t$ as follows:

$$
D L_{t}=\sum_{s=0}^{t-1} L_{s}^{s p} \cdot d_{s, s p}+L_{s}^{s} \cdot d_{s, s}
$$

and transform it into a yearly repayment stream, assuming a 10 year horizon and using the student loan interest rate prevailing over each relevant period. The rate of interest was equal to $8 \%$ for the 1979 cohort and 5\% for the 1997 cohort. We denote the yearly repayment by $\digamma_{t}\left(D L_{t}\right)$ and reduce post-college wages by the repayment level which depends indirectly on past enrollment decisions and on past-borrowing. Formally, the repayment, $\digamma_{t}\left(D L_{i t}\right)$, is computed as

$$
\digamma_{t}\left(D L_{i t}\right)=D L_{i t} \cdot\left(r+\frac{r}{(1+r)^{10}-1}\right)
$$

where $r$ is the interest rate. Forward looking agents thereby internalize the cost of enrolling in higher education by expecting a lower net wage once leaving school.

The utilities are written as follows

$$
\begin{aligned}
& U_{i t}^{f}=\bar{U}_{i t}^{f}+\varepsilon_{i t}^{f}=\alpha_{0 i}^{f}(t)+\ln \left(\alpha_{1}^{f} \cdot\left(W_{i t}-\digamma_{t}\left(D L_{i t}\right)\right)+\varepsilon_{i t}^{f}\right. \\
& U_{i t}^{p}=\bar{U}_{i t}^{p}+\varepsilon_{i t}^{p}=\alpha_{0 i}^{p}(t)+\ln \left(\alpha_{1}^{p} \cdot\left(W_{i t}-\digamma_{t}\left(D L_{i t}\right)\right)+\varepsilon_{i t}^{p}\right.
\end{aligned}
$$

where $\varepsilon_{i t}^{f}$ and $\varepsilon_{i t}^{p}$ idiosyncratic random shocks. To estimate the model, we fix $\alpha_{1}^{f}$ to 1 and let $\alpha_{1}^{p}$ to 0.5 . The heterogeneity terms measuring individual specific differences in the valuation of work intensity $\left(\alpha_{0 i}^{f}(t)\right.$ and $\left.\alpha_{0 i}^{p}(t)\right)$ depend on $t$ as we allow educational attainment to affect the disutility of working full-time or part-time. They are given by the following expression:

$$
\alpha_{0 i}^{p}(t)=\tilde{\alpha}_{i}^{p}+\alpha_{h}^{p} \cdot h_{i t}+\alpha_{a}^{p} \cdot a_{i t}+\alpha_{c}^{p} \cdot c_{i t}
$$




$$
\alpha_{0 i}^{f}(t)=\tilde{\alpha}_{i}^{f}+\alpha_{h}^{f} \cdot h_{i t}+\alpha_{a}^{f} \cdot a_{i t}+\alpha_{c}^{f} \cdot c_{i t}
$$

where $\tilde{\alpha}_{i}^{p}$ and $\tilde{\alpha}_{i}^{f}$ play the role of unobserved heterogeneity in the valuation of part-time work and full-time work. The variables $h_{i t}, a_{i t}$, and $c_{i t}$ indicate the highest grade attained by date $t$ (high school graduates, college associates, and college graduates respectively) and $\alpha_{h}^{p}, \alpha_{h}^{f}, \alpha_{a}^{p}, \alpha_{a}^{f}, \alpha_{c}^{p}$ and $\alpha_{c}^{f}$ are associated parameters to be estimated.

\section{Non-Market Time}

Finally, the utility of household production (state $\mathrm{nm}$ ) is assumed to depend on schooling and on unobserved heterogeneity:

$$
U_{i t}^{N M}=\alpha_{i}^{n m}+\alpha_{h}^{n m} \cdot h_{i t}+\alpha_{a}^{n m} \cdot a_{i t}+\alpha_{c}^{n m} \cdot c_{i t}+\varepsilon_{i t}^{n m}
$$

\section{The Skill Production Functions and Wages}

Each wage (log) equation is interpreted as a skill production function mapping individual heterogeneity and accumulated full-time and part-time experience, which are denoted $F_{t}$ and $P_{t}$ respectively, into log wages. As the return to part-time and full-time experience depend on each type of schooling, our specification is more general than standard Mincer models. .

The wage equations are equal to the following:

$$
\begin{gathered}
w_{i t}^{d}=\bar{w}_{i t}^{d}+\varepsilon_{i t}^{d} \text { (HS dropouts) } \\
w_{i t}^{h}=\bar{w}_{i t}^{h}+\varepsilon_{i t}^{h} \text { (HS graduates) } \\
w_{i t}^{a}=\bar{w}_{i t}^{a}+\varepsilon_{i t}^{a} \text { (Associates) } \\
w_{i t}^{c}=\bar{w}_{i t}^{c}+\varepsilon_{i t}^{c} \text { (College Graduates) }
\end{gathered}
$$

with

$$
\bar{w}_{i t}^{d}=\lambda_{i}^{d}+\lambda_{F}^{d} \cdot F_{i t}+\lambda_{P}^{d} \cdot P_{i t}+\lambda_{s}^{d} \cdot d_{i t, f}
$$




$$
\begin{aligned}
& \bar{w}_{i t}^{h}=\lambda_{i}^{h}+\lambda_{F}^{h} \cdot F_{i t}+\lambda_{P}^{h} \cdot P_{i t}+\lambda_{s}^{h} \cdot d_{i t, s} \\
& \bar{w}_{i t}^{a}=\lambda_{i}^{a}+\lambda_{F}^{a} \cdot F_{i t}+\lambda_{P}^{a} \cdot P_{i t}+\lambda_{s}^{a} \cdot d_{i t, f} \\
& \bar{w}_{i t}^{c}=\lambda_{i}^{c}+\lambda_{F}^{c} \cdot F_{i t}+\lambda_{P}^{c} \cdot P_{i t}+\lambda_{s}^{c} \cdot d_{i t, f}
\end{aligned}
$$

The individual specific parameters $\left(\lambda_{i}^{d}, \lambda_{i}^{h}, \lambda_{i}^{a}, \lambda_{i}^{c}\right)$ measure unobserved heterogeneity affecting wages. The group-specific log skill price is absorbed into each individual specific intercept terms when estimating the model on each cohort separately. The parameters $\lambda_{s}^{d}, \lambda_{s}^{h}, \lambda_{s}^{a}$ and $\lambda_{s}^{c}$ act as shift parameters that allow full-time wages to differ from part-time wages.

\section{Stochastic Choices}

- Utility Shocks: The elements of the vector of error terms $\left\{\varepsilon_{i t}^{s}, \varepsilon_{i t}^{s p}, \varepsilon_{i t}^{s f}, \varepsilon_{i t}^{f}, \varepsilon_{i t}^{p}, \varepsilon_{i t}^{n m}\right\}$ are assumed to be i.i.d. and to follow an extreme-value distribution (Rust, 1987).

- Wage Shocks: The stochastic wage shock vector is $\varepsilon_{i t}^{w}=\left\{\varepsilon_{i t}^{d}, \varepsilon_{i t}^{h}, \varepsilon_{i t}^{a}, \varepsilon_{i t}^{c}\right\}$ and all components are assumed to be i.i.d. Normal with mean 0 and with standard deviations $\sigma^{d}, \sigma^{h}, \sigma^{a}$ and $\sigma^{c}$.

\section{Grade Progression Technology and Educational Standards}

We model grade accumulation as a stochastic binary outcome that depends on current grade attainment (whether in high school or post-high school), on contemporaneous hours worked and on unobserved heterogeneity. We define an indicator, $g_{t}$, equal to 1 when grade advancement is realized $\left(G_{t+1}=G_{t}+1\right)$ and 0 when not $\left(G_{t+1}=G_{t}\right)$, and write the transition probability as follows:

$$
\begin{aligned}
\operatorname{Pr}\left(g_{t}=\right. & 1 \mid \text { in school })= \\
\operatorname{Pr}\left(G_{t+1}=\right. & \left.G_{t}+1 \mid \text { in school }\right)= \\
& \frac{\exp \left(g_{i}+g_{1} \cdot I\left(12 \leq G_{i t}\right)+g_{2} \cdot d_{t, s p}+g_{3} \cdot d_{t, s f}\right)}{1+\exp \left(g_{i}+g_{1} \cdot I\left(12 \leq G_{i t}\right)+g_{2} \cdot d_{t, s p}+g_{3} \cdot d_{t, s f}\right)}
\end{aligned}
$$


where $g_{i}$ is an unobserved heterogeneity term affecting grade accumulation, $g_{1}$ is a parameter allowing the rate of grade progression to differ between high school and college and $g_{2}$ and $g_{3}$ measure the impact of part-time and full-time work during school on grade progression.

\section{Bellman Equations}

We model choices from age 16 until 28. The problem is solved using recursive methods, and optimal choices may be characterized by a Bellman equation. For each possible choice, there is a specific value function, $V_{t}^{k}\left(\Omega_{t}\right)$, equal to

$$
\begin{aligned}
V_{t}^{k}\left(\Omega_{t}\right) & =\bar{U}_{t}^{k}+\varepsilon_{t}^{k}+\beta E V_{t+1}\left(\Omega_{t+1} \mid d_{k t}=1\right) \text { for } k=s, s p, s f, n m, p, f \\
& =\bar{V}_{t}^{k}+\varepsilon_{t}^{k}
\end{aligned}
$$

where $\bar{V}_{t}^{k}=\bar{U}_{t}^{k}+\beta E V_{t+1}\left(\Omega_{t+1} \mid d_{k t}=1\right)$ and where $\Omega_{t}$ denotes the set of all relevant state variables at date $t$ (random shocks, accumulated periods in each state, accumulated debt-load, and grade level). The future component is defined as follows

$$
\begin{aligned}
& E V_{t+1}\left(\Omega_{t+1} \quad \mid \quad d_{k t}=1\right) \\
& =E \max \left\{V_{s t+1}^{s}(.), V_{t+1}^{s p}(.), V_{t+1}^{s f}(.), V_{t+1}^{n m}(.), V_{t+1}^{p}(.), V_{t+1}^{f}(.) \mid d_{k t}=1\right\}
\end{aligned}
$$

where $\beta$ is the discount factor, and where $\Omega_{t}$ is the set containing all state variables known by the agent at $t$.

Finally, to estimate the model, we need to impose a terminal condition. As pointed out in Magnac and Thesmar (2002), a free terminal value function may introduce identification problems. Within the context of a schooling model, specifying a terminal value function as a flexible polynomial function of state variables would be problematic because it would be hard to distinguish between an agent deciding to educate himself because of a high value of the non-pecuniary utility of attending higher education and another one doing so because education conveys a higher expected utility beyond the terminal date. Both of these are identified from the propensity to obtain more or less education after conditioning on the monetary component of the skill premium. Separating them would be tenuous.

To proceed, we assume that the terminal value is the logarithm of the difference between the full-time wage, expressed at accumulated schooling 
and experience levels of the last period, and the residual debt-load. That is

$$
V_{T=a g e 29}=E \log \left(w_{i, a g e 29}-\left(D L_{a g e 29}-\sum_{s=a g e 16}^{a g e 28} \digamma_{i}\left(D L_{i s}\right)\right)\right.
$$

It follows that the terminal value function, $V_{T=a g e 29}$, does not incorporate any additional parameter and that identification of the structural parameters is facilitated by this sort of assumption. Without it, individuals would be induced to raise consumption at unreasonable levels while in school, and run abnormally high debt-levels.

\subsection{Estimation}

To facilitate estimation, we follow Sullivan $(2006,2010)$ and implement an interpolation method in the spirit of Keane and Wolpin (1997) and which is adapted for models with Extreme Value utility shocks (Rust, 1987). Like all interpolation methods, it first requires to solve value functions at a limited subset of the state space and use these values within a regression to approximate value functions for the remaining elements of the state space.

\section{First Step}

First, and in order to evaluate the value functions, we simulate the distribution of $\varepsilon_{i t}^{w}=\left\{\varepsilon_{i t}^{d}, \varepsilon_{i t}^{h}, \varepsilon_{i t}^{a}, \varepsilon_{i t}^{c}\right\}$ using $A$ antithetic draws for each component. ${ }^{15}$ Defining $\bar{V}_{t}^{k}(a)$ as the deterministic part of the intertemporal utility of option $k$ conditional on one realization $(a)$ of the vector $\varepsilon_{i t}^{w}$, the expected maximum utility achievable in period $t$ is equal to

$$
E V_{t}(a)=\tau \cdot\left(\gamma+\ln \left\{\sum_{k} \exp \left(\frac{\bar{V}_{t}^{k}(a)}{\tau}\right)\right\}\right)
$$

where

$$
\bar{V}_{t}^{j}(a)=V_{t}^{j}(a)-\varepsilon_{t}^{j} \text { for } k=s, s p, s f, n m, p, f
$$

and where $\tau$ is the scale of the extreme-value distribution and $\gamma$ is Euler's constant.

\footnotetext{
${ }^{15}$ In practice, we set $A$ to 20.
} 
The expected value function, $E V_{t}$, is obtained by averaging each $E V_{t}(a)$ over a total number of draws:

$$
E V_{t}=\frac{1}{A} \sum_{a=1}^{A} \tau \cdot\left(\gamma+\ln \left\{\sum_{k} \exp \left(\frac{\bar{V}_{t}^{k}(a)}{\tau}\right)\right\}\right)
$$

Conditional on one realization $(a)$, the probability of choosing any option $l$, denoted $\operatorname{Pr}\left(d_{l t}=1 ; a\right)$, takes the well-known Logit form and are expressed as follows:

$$
\operatorname{Pr}\left(d_{l t}=1 ; a\right)=\frac{\exp \left(\bar{V}_{t}^{l}(a)\right)}{\sum_{k} \exp \left(\bar{V}_{t}^{k}(a)\right)}
$$

Second Step

Simulation methods are known to take much computer time as the structure of the model requires to simulate a reasonable number of components of the wage shock for each individual (or each type of individual) and time period. As we focus on the role of comparative advantages, our approach also requires considering a reasonable number of types. On top of this, the number of elements in the state space is relatively large as we model choices annually from age 16 to 28 .

This brings the need for a second step. Sullivan (2006) shows that it is possible to take advantage that the utility shocks are distributed Extreme Value to design an interpolation algorithm easy to implement.

Define the following quantity

$$
\bar{V}_{t}^{* k}=\left.\bar{V}_{t}^{k}(a)\right|_{\varepsilon_{i t}^{d}=0, \varepsilon_{i t}^{h}=0, \varepsilon_{i t}^{a}=0, \varepsilon_{i t}^{c}=0}
$$

and denote by $\Psi^{*}($.$) the closed-form solution to the Emax expression after$ removing the wage shocks. In such a case, the Emax has the usual closedform expression introduced in Rust (1987), and we obtain

$$
\Psi^{*}(.)=\tau \cdot\left(\gamma+\ln \left\{\sum_{k} \exp \left(\frac{\bar{V}_{t}^{* k}}{\tau}\right)\right\}\right)
$$

Sullivan's interpolation method consists in regressing $E V_{t}$ on an intercept term and $\Psi^{*}($.$) , and use the parameters to generate predicted Emax's as$ follows

$$
E \hat{V}_{t}=\hat{\omega}_{0 t}+\hat{\omega}_{1 t} \cdot \Psi^{*}(.)
$$


where $\omega_{0 t}$ and $\omega_{1 t}$ are parameters allowed to vary with $t$. Sullivan shows that the interpolation method works well with a relatively small number of state space elements (for instance 1\%) as the $\mathrm{R}$ squares of those regressions range between 0.96 and 0.99 .

We are now in position to describe the likelihood function. For each individual $i$ at date $t$, the data are contained in a vector of observed outcomes $O_{i t}=\left\{d_{i s t}, d_{i s p t}, d_{i s f t}, d_{i p t}, d_{i f t}, d_{i n m t}, g_{i t}, w_{i t}^{O}\right\}$ where $w_{i t}^{O}$ denotes observed wage outcome. To estimate the model, we set $M$ to 4 .

The likelihood function for individual $i\left(L_{i}\right)$ is given by

$$
L_{i}(.)=\sum_{m=1}^{M} \prod_{t=1}^{T} \operatorname{Pr}\left(O_{i t} \mid \text { type } m\right) \cdot \operatorname{Pr}\left(\text { type } m \mid G_{16}, A F Q T\right)
$$

where

$$
\operatorname{Pr}\left(\text { type } m \mid G_{16}, A F Q T\right)=\frac{\exp \left(\tilde{p}_{m}+\tilde{p}_{m G} \cdot G(16)+\tilde{p}_{m A} \cdot A F Q T\right)}{1+\sum_{j=2}^{M} \exp \left(\tilde{p}_{j}+\tilde{p}_{j G} \cdot G(16)+\tilde{p}_{j A} \cdot A F Q T\right)}
$$

The total likelihood is the product of each $L_{i}($.$) over all individuals. Struc-$ tural parameters are obtained by maximizing the logarithm of the likelihood function using Fortran routines.

\section{$5 \quad$ Fitting the Model to the 1979 and the 1997 Cohorts}

In this section, we review some of the parameter estimates as well as the main features of the model when implemented on the 1979 and the 1997 cohorts separately. The model incorporates about 80 parameters when estimated on a single cohort. As in Sullivan $(2006,2010)$, we compute the value functions at $1 \%$ of the state space and use regression methods to perform interpolations at each specific age. As reported in Sullivan (2006), the values of the $R$ squared for each regression fluctuate between 0.93 and 0.99. All structural parameters are found in appendix.

Many findings are coherent with those reported in the structural literature since most structural schooling models published in the last 20 years have been estimated using the 1979 cohort of the NLSY. This is why we focus our comments mostly on the evolution of some key parameters. 


\subsection{Model Fit}

In Table 4, we report the empirical and predicted frequencies summarizing individual choices between age 16 and 28 . As should be relatively clear upon examining the difference between empirical and predicted frequencies, the fit of the model is excellent. This is particular true for the 1979 cohort.

The model captures the main changes which took place between the early 1980 's and the early 2000's. For instance, it can account for the decrease in the incidence of full-time work (with no school) from $45 \%$ to $36 \%$ that took place over that period. It also predicts the significant increase in home production which took place over the same period (from $10 \%$ to $16 \%$ ).

\subsection{Utility of Attending School}

In the model, the utility of attending education is defined as the logarithm of consumption (net of tuition) when in high school or when in college. As is the case for every structural schooling model in the literature, the consumption level cannot be inferred directly from data but must be treated as a free quantity to be estimated. It is interpreted as the level of consumption (including goods and non-pecuniary value of attending education) that can rationalize observed choices, given education costs and borrowing.

The average net consumption levels achieved in college (by type) are reported in Table 5. To evaluate it for those enrolled in school and working at the same time (either part-time or full-time), we use average wages for those working at age $20 .{ }^{16}$ As documented in Table 5, the estimated consumption levels (expressed on a per-hour basis) depend heavily on labor supply effort but also on unobserved heterogeneity.

For the 1979 cohort, the type specific consumption level for the School/NoWork option ranges from $\$ 1.06$ (type 3 ) to $\$ 12.89$ (type 4 ). The average taken over all types is equal to $\$ 3.79$. The net consumption level of type 4 individuals is therefore about $\$ 10$ higher than other types. On a yearly basis (assuming 2000 hours), this would represent a $\$ 20,000$ difference between type 4 individuals and all other types.

Interestingly, and despite the amount of money earned when working fulltime or part-time, the level of net consumption achieved when not working is very close to the level of those who work. The average consumption when

\footnotetext{
${ }^{16}$ These values are equal to $\$ 10.20$ in the 79 cohort and $\$ 9.98$ in the 97 cohort.
} 
enrolled and working part-time is $\$ 4.83$, but more surprisingly, the average consumption for those enrolled and working full-time is $\$ 4.98$. We interpret these results as follows. Those who have a high utility of attending school without working most probably are endowed with a higher level of nonpecuniary utility of attending college than those who work. For instance, type 4 individuals who have a high taste for enrollment with no work have the lowest level of utility (or total consumption) of enrolling with part-time work.

Another explanation could be that parental transfers, intrinsically unobserved, are tied to labor supply while in school. While differences in parental transfers may also be an appealing reason for the lack of major difference in consumption, it is impossible to say if it is labor supply that responds to transfers or parents who adjust transfers according to labor supply. ${ }^{17}$

The evolution of the per-period utility of attending college is particularly interesting, given that our model incorporates an increase of approximately $100 \%$ in college costs and a related increase in borrowing needs based on labor supply. There is overwhelming evidence that the net utility of attending college has increased sharply upon examination of the 1997 cohort estimates. This is true overall and is also verified for all possible labor supply modalities. For instance, the net consumption levels of those who do not work and of those who work part-time have increased by about $\$ 10$ on a per-hour basis to reach $\$ 13.4$ and $\$ 13.20$ respectively. Although the net consumption level of those who work full-time while in school is found to be lower (at \$8.97), it has increased by $\$ 4$.

Overall, our estimates disclose a strong growth in the utility of attending higher education, as indicated by its associated consumption levels. Interestingly, this spectacular growth exists despite the large increase in tuition (and related debt level) which has been observed over that period. To see this, recall that the average cost per year of college has increased from $\$ 3,648$ to $\$ 7,042$ between the early 1980's and the early 2000's. On a per-hour basis, this represents a burden of about $\$ 1.83$ in the early 1980's and $\$ 3.5220$ years later.

To give a concrete example, an individual who would have borrowed the entire cost of college for 4 years, would need to repay about $\$ 2,174$ per year in the 1979 cohort and $\$ 3,648$ per year in the 1997 cohort. On a per-

\footnotetext{
${ }^{17}$ As far as we know, this issue has never been adressed empirically.
} 
hour basis (for someone working 2000 hours per year), these would imply an hourly repayment of $\$ 1.09$ repayment for 1979 and $\$ 1.82$ for $1997 .{ }^{18}$ Despite all this, individuals tend to enroll in college with larger probabilities in the early 2000's than in the early 1980's. Our estimates indicate precisely that they do so largely because the intrinsic taste for (or the disutility of) college has increased (decreased) significantly.

However, as one never observes all relevant parental transfers, it is impossible to know if this increase in utility is caused by an increase in good's consumption or an increase in the non-monetary component of education. However, and no matter what, these estimates imply that it is hardly possible to explain changes in education patterns without appealing to changes in the net utility of attending higher education.

While no other paper has documented precisely the evolution of the utility of attending school, many authors have documented its importance for a particular cohort. It is therefore important to compare our results to those found in the literature. Results are often difficult to compare as some authors report the per-period utility of attending school while others have tried to separate benefits and costs or tried to isolate the college consumption value itself.

In a seminal piece, Keane and Wolpin document that the contemporaneous utility of attending schooling for a 16 -year-old ranges from $\$ 5,000$ to $\$ 15,000$ (in 1987 dollars) depending on individual type. Their approach does not allow them to separate the consumption value from goods consumption. Similar results, for the 1979 cohort of the NLSY, are reported in Eisenhauer, Heckman and Vytlacil (2015).

Using data on consumption expenditures during and after college, desired borrowing amounts, beliefs about post-college earnings, and elicited riskaversion and time preference parameters from students who entered Berea College in 2000 and 2001, Gong, Lochner, Stinebrickner and Stinebrickner (2019) are able to separate the consumption value of college from other components. They find an average annual consumption value of college as high as $\$ 11,600$ (in 2001 dollars) with considerable heterogeneity across students.

Using micro data from the high school classes of 1992 and 2004, matched to information on four-year colleges in the U.S., Jacob, McCall and Stange

\footnotetext{
${ }^{18}$ In appendix, we report detailed statistics about predicted debt-loads and repayments implied by behavior.
} 
(2018) estimate the actual determinants of the consumption value of college attendance. They find that many students do appear to value college consumption amenities such as dormitories, sports facilities and other nonacademic services.

\subsection{Non-Market Time}

The average values (over types) of non-market time, reported in Table 6, indicate that household productivity (or the value of leisure) is increasing with education. For instance, the value of non-market time of a college graduate in the 1979 cohort was 4 times as large as that of a high school drop-out ( $\$ 4.29$ vs $\$ 0.93$ ). However, the values remain generally much lower than the per-period utilities of attending education.

When compared with those of the 1979 cohort, the average values implied by structural estimates of the 1997 cohort indicate not only that education raises home productivity but that the value of home production has increased for all education levels, except college graduates. The value of home time of high school drop-outs, high school graduates and college associates have increased by about $\$ 0.50$ on a per-hour basis (about $\$ 1,000$ per year). The value of home time of college graduates dropped by more than $\$ 1$ but remains much higher than for other education groups (more than $\$ 6,000$ on a yearly basis). This general increase in the value of non-market time is not that surprising as we already noted that periods of non-market activities have become more frequent in the early 2000's than in the early 1980's.

\subsection{Grade Progression}

The grade progression probabilities in college obtained for 3 different labor supply modalities (no work, work part-time and work full-time) are reported in Table 7. There are two major findings to report.

First, and at all three labor supply modalities, the grade progression probabilities have decreased between the 1980's and the early 2000's. For those who did not work, the average grade progression probabilities have dropped from 0.76 to 0.66 . This is also true for those working part-time (from 0.67 to 0.55 ) and especially for those working full-time (from 0.51 to $0.376)$. 
Second, and within each cohort, there is a substantial difference in grade progression probabilities explained by labor supply while in school. As an illustration, the difference in average grade progression probabilities between those who did not work and those who worked full-time was equal to 0.25 in the early 1980's and about 0.28 in the early 2000's. The deficit between those who worked part-time and those who did-not work was smaller (about 0.10 ), but was always sufficiently high to create a significant impact on age at graduation.

This latter finding is particularly interesting. The strong negative impact of working hours on grade advancement, which is especially significant for those working full-time, is most likely a key determinant of the willingness to borrow as a source of education financing. Forward looking agents must incorporate this feature when solving the intertemporal time allocation problem. That is without this strong negative impact, young individuals would have less incentive to borrow (and build up student debt) and would instead be more likely to work while enrolled.

Finally, our model does not incorporate any information friction with respect to individual specific abilities and tastes. Another interpretation of the relatively high level of attrition may be a form of learning through college grades and wages. That is individuals may leave or re-enter college as a result of the arrival of new information on their ability and productivity. This sort of approach is followed in Arcidiacono, Aucejo, Maurel and Ransom (2019). ${ }^{19}$

\subsection{Changes in Education Premia}

We now turn to a comparison of the college-high school premium and the returns to experience across cohorts. Because a Roy model implies that a portion of the returns to college graduation is actually explained by differences in returns to experience, this means that any measure of the college premium is bound to depend on the specific age at which it is measured. In what follows, we evaluate the type-specific college-high school premium at 5 years of full-time experience in order to obtain an illustration of the premium realized over the early phase of the life-cycle. The returns to ex-

\footnotetext{
${ }^{19}$ Aucejo et al (2019) report that the elimination of informational frictions would increase the college graduation rate by 9 percentage points, and would increase the college wage premium by 32.7 percentage points through increased sorting on ability.
} 
perience needed to compute the college-high school premium are reported in Table 8, while the premia are reported in Table 9A.

First, and after incorporating relevant returns to experience, we find that the college-high school premium, which is about 50\% on average for the 1979 cohort, differs widely across types. This is in full coherency with our specification of the skill production functions as a Roy model. Type 4 individuals are those who have the highest return to college graduation $(76.6 \%)$ while type 1 and type 3 have the lowest premia (36\% and 37\%). Type 2 individuals are endowed with a college premium of about $57.6 \%$.

To fully understand the nature of the college-high school premium, it is informative to examine Table 8 , in which the evolution of the returns to early life-cycle experience are reported. The college premium obtained for the 1979 cohort is largely explained by difference in returns to full-time experience between college graduates (equal to 0.102) and high school graduates (0.042). It is therefore largely absorbed by the supplementary wage growth experienced by college graduates (6\% advantage per year of experience). Without it, the college-high school premium at labor market entrance would be close to $15 \%$.

Secondly, the college-high school premium obtained for the 1997 cohort differs also widely by type. It is however higher on average. The highest premium, above $100 \%$, is observed for type 2 individuals and the average premium in the population has increased from $50 \%$ to $58 \%$. Our results are coherent with Ashworth et al. (2020), who report an increase in the return to an additional year of schooling and the return to a high school degree in their analysis of the 1979 and 1997 cohort. However, their specification of the wage equation (they focus on local returns), the treatment of unobserved heterogeneity and the inclusion of GED's in the high school graduate group (we treat them as drop-outs), render further comparisons difficult.

Returning to Table 8 and Table 9A, there is however a big difference between the 1979 and the 1997 premia. Unlike what was observed for the early 1980's, the college-high school premium of the early 2000's is not primarily explained by differences in returns to experience. Indeed, and consistent with the recent literature on age earnings profiles, the returns to full-time experience have decreased for all education group. This is particular true for college graduates as their return to experience (full-time) dropped from $10.2 \%$ to $6.5 \%$. Returns to experience of high school graduates have also dropped, but by only 1 percentage point (4.2\% to $3.1 \%)$. As a result, the 
high school college premium measured at entrance (with no experience) is estimated to be about $41 \%$, as opposed to $15 \%$ in the early 1980 's. Put differently, the college-high school premium at entrance in the early 1980's accounted for $1 / 3$ of the total premium measured after 5 years of full-time work. In the early 2000's, it accounted for more than $2 / 3$ of it. ${ }^{20}$ This finding is therefore coherent with the gradual flattening of US age earnings profiles noted by different authors (see Kong, Ravikumar and Vandenbroucke, 2017), Beaudry, Green and Sand (2014) and Kambourov and Manovskii (2009).

In Table 9A, we also report the type specific high school completion premia for both cohorts. Because differences in returns to experience between drop-outs and high school graduates are very small, computing the 1979 and 1997 high school completion premia at market entrance or after 5 years of full-time experience delivers practically the same answer. Not surprisingly, the high school completion premium is much smaller than the college high school premium. Our population average estimates, equal to $19.2 \%$ in 1979 and $20.0 \%$ in 1997 , also indicate that the high school completion premium was stable over the period that we considered.

\subsection{Changes in Relative College Quality}

Until now, all the discussion about college and high school graduation premia concerned ex-ante returns by type (or averages over types). Those estimates characterize the distribution of returns in the population. There is however no reason to believe that the realized college-high school premium (by actual college graduates) should necessarily be equal to the population average. Using simulated outcomes, it is easy to compute the realized premium for any group. In the econometric literature on treatment effects, those parameters are usually referred to as "Average Treatment Effects for the Treated". We now compare the former with the latter in order to detect their relative evolution.

In the last 2 rows of Table 9A, we report the average college-high school premium for college graduates as well as the average high school premium

\footnotetext{
${ }^{20}$ One implication of the flattening of age-earnings profiles may be a modification of the relationship between college participation and the rate of time preference. As in most structural models, we assume a common discount factor and set it to 0.95 and are therefore unable to address this issue. As far as we know, this sort of question has never been addressed.
} 
for high school graduates. First, we note that in the 1979 cohort, the difference between the realized college premium $(72 \%)$ and the population average premium $(50 \%)$ is positive and relatively large. This is not surprising as it is fully coherent with individual decisions driven by comparative advantages. Although actual high school graduates experience a higher high school graduation premium $(20.3 \%)$ than the population average $(19.2 \%)$, the difference remains small and points toward actual high school graduates being fairly representative of the average population.

One question that motivates this paper is the evolution of educational (college) selectivity. Although the model specification that imposes no restriction across cohorts is not directly informative about the evolution of the human capital level across cohorts (absolute quality), it can still provide useful information about the evolution of the distance between the realized premia and the population average premia (what we referred to as the evolution of the relative quality of college attendants and graduates). For instance, a positive difference between the realized college premium and the population average college premium may indicate a high degree of college selectivity.

The comparisons disclose an interesting paradox. Although the population average college premium shifted to the right, going from $50 \%$ to $58 \%$, the college premium of actual college graduates has shifted to the left, going from $72 \%$ to $54 \%$. It is important to note that not only is the average college-high school premium of the 1997 cohort college graduates much lower than that of the 1979 cohort, but the gap between average and realized college premia, which was about 20 percentage points in the 1980's, has been reduced to a 4 percentage points difference in the early 2000 's. The increase in the average college premium in the population is most likely affected by the fact that measuring it around age 28 limits significantly the impact of the relative flattening of age earnings profiles of college graduates. However, because our specification incorporates heterogeneity in the wage intercept only, the convergence of the realized college premium of actual college graduates and the population average is likely to be robust to changes of age at which they are measured.

While the empirical literature has focussed on measuring the collegehigh school premium, an alternative is to measure changes in relative cohort quality of college associates and graduates using simple differences between realized wages (log) of any education group and the population average counterpart. The latter has the advantage of not being affected by potential high 
school wages and is also the classical comparison used to detect the presence of positive or negative selection. In Table 9B, we report those differences obtained for both college associates and college graduates. In the early 1980's, the average wage of college associates (in a college associate job) was slightly above the population average as the differential was about $3 \%$ and therefore pointed toward the existence of positive selection among college associates. In the 2000 cohort, the ordering was reversed and the sub-population of college associates was earnings $5 \%$ less than the population average. Positive selection was transformed into negative selection.

A similar tendency is also observed for college graduates. In the 1979 cohort, there was strong positive selection characterizing college graduates, as they earned $8 \%$ more than the population average in a college job. By the early 2000, college graduates earned only $2 \%$ more than the population average and positive selection prevailing in the early 1980's had almost entirely vanished. Our estimates therefore point to a decline in relative quality of both college associates and college graduates and may be explained by the expansion of the US college system which may have attracted students with lower market abilities (Hoxby, 2009, Babcock and Marks, 2011) but also by the expansion of higher education financial aid programs (Dynarski and Scott-Clayton, 2013). It essentially means that the more recent cohort of college graduates and college associates are increasingly representative of the population average. This was not the case in the early 1980's.

\subsection{Some Implication of the Flattening of Age Earn- ings Profiles}

As stated earlier, one of the most important changes in education attendance patterns has been an increase in the number of college students. This has been accompanied by an increase in the incidence of work while in school and an increase in age at college graduation. This however raises the following question: has the impact of an increase in age at graduation on wages changed over the period covered in our analysis?

The answer is far from obvious because individuals in the recent cohort are known to have accumulated less full-time experience outside school by age 28 (see Table 2), but have also accumulated more part-time work experience while in school. On top of this, because the return to full-time experience of 
college graduates appear to have decreased more than returns to experience of other education groups, the wage impact of delayed college graduation implied by the model is difficult to evaluate.

To answer this question, we use simulated outcomes until age 28 and regress wages on age at college graduation. To eliminate the impact of unobserved heterogeneity, we also perform regression specifications that condition on type. The results, found in Table 10, produces overwhelming evidence in favor of a decrease in the effect of late graduation on early life-cycle wages. In the early 1980's, a one year delay in college graduation reduced wages by $4 \%$ (whether heterogeneity is ignored or taken into account).

However, in the early 2000's, the effect of a one year delay had practically vanished. Without conditioning on types, our estimate indicates that graduating one year later has a minuscule (insignificant) impact on wages. With type indicators, the estimate implies a $2 \%$ reduction but is also insignificant. 
Table 4

Model Fit:

Predicted and Empirical Frequencies by Age 28

\begin{tabular}{|c|c|c|c|}
\hline & & \multicolumn{2}{|c|}{ Cohort } \\
\hline Individual Choices & & $\mathbf{1 9 7 9}$ & $\mathbf{1 9 9 7}$ \\
\hline School, no work & Model & 0.189 & 0.206 \\
\hline & Data & 0.170 & 0.193 \\
\hline & & & \\
\hline School, part-time work & Model & 0.126 & 0.146 \\
\hline & Data & 0.115 & 0.121 \\
\hline & & & \\
\hline School, full-time work & Model & 0.069 & 0.103 \\
\hline & Data & 0.050 & 0.062 \\
\hline & & & \\
\hline No School, Part-time work & Model & 0.095 & 0.083 \\
\hline & Data & 0.116 & 0.113 \\
\hline & & & \\
\hline No School, Full-time work & Model & 0.420 & 0.313 \\
\hline & Data & 0.447 & 0.355 \\
\hline & & & \\
\hline & Model & 0.101 & 0.150 \\
\hline & Data & 0.102 & 0.156 \\
\hline
\end{tabular}


Table 5

Total Consumption during Education Attendance

by Labor supply Status

(in $\$$ per hour)

\begin{tabular}{|lc|c|c|c|}
\multicolumn{1}{l}{} & \multicolumn{1}{c}{$\begin{array}{c}\text { Type } \\
\text { Proportions }\end{array}$} & $\begin{array}{c}\text { School } \\
\text { No Work }\end{array}$ & $\begin{array}{c}\text { School } \\
\text { Part-Time Work }\end{array}$ & $\begin{array}{c}\text { School } \\
\text { Full-Time Work }\end{array}$ \\
\hline 1979 cohort & & & & \\
\hline type 1 & 0.392 & $\$ 3.71$ & $\$ 4.87$ & $\$ 5.08$ \\
\hline type 2 & 0.217 & $\$ 3.13$ & $\$ 3.39$ & $\$ 4.53$ \\
\hline type 3 & 0.287 & $\$ 1.06$ & $\$ 4.38$ & $\$ 5.15$ \\
\hline type 4 & 0.104 & $\$ 12.89$ & $\$ 8.95$ & $\$ 5.07$ \\
\hline Average & - & $\$ 3.78$ & $\$ 4.83$ & $\$ 4.98$ \\
\hline \hline 1997 cohort & & \multicolumn{4}{l}{} \\
\hline type 1 & 0.118 & $\$ 14.53$ & $\$ 11.96$ & $\$ 7.28$ \\
\hline type 2 & 0.313 & $\$ 13.60$ & $\$ 13.35$ & $\$ 9.45$ \\
\hline type 3 & 0.454 & $\$ 12.73$ & $\$ 13.26$ & $\$ 9.37$ \\
\hline type 4 & 0.114 & $\$ 14.52$ & $\$ 13.83$ & $\$ 7.77$ \\
\hline Average & - & $\$ 13.42$ & $\$ 13.20$ & $\$ 8.97$ \\
\hline
\end{tabular}

Note: Total consumption is interpreted as the sum of goods consumption plus the monetary equivalent of the non-pecuniary utility of attending college (beyond grade 14).

Note: Type probabilities are computed at the average AFQT value and at the model value of age 16 grade completed (10 years of schooling).

Table 6

Education and the Value of Non-Market time (in $\$$ per hour)

\begin{tabular}{|l|c|c|c|c|}
\hline & Drop-Outs & High School & Associate & College \\
\hline & & & & \\
\hline 1979 Cohort & $\$ 0.93$ & $\$ 1.45$ & $\$ 1.92$ & $\$ 4.29$ \\
\hline & & & & \\
\hline \hline & & & & \\
\hline & $\$ 1.44$ & $\$ 1.94$ & $\$ 2.50$ & $\$ 3.11$ \\
\hline
\end{tabular}

Note: The value of non-market time are measured on a per-hour basis and averaged over unobserved types. 
Table 7

\section{Grade Progression Probabilities in College} by Type in each Cohort

\begin{tabular}{|c|c|c|c|}
\hline & $\begin{array}{c}\text { School } \\
\text { No Work }\end{array}$ & $\begin{array}{l}\text { School } \\
\text { Part-Time Work }\end{array}$ & $\begin{array}{c}\text { School } \\
\text { Full-Time Work }\end{array}$ \\
\hline \multicolumn{4}{|c|}{1979 cohort } \\
\hline type 1 & 0.808 & 0.720 & 0.553 \\
\hline type 2 & 0.638 & 0.519 & 0.344 \\
\hline type 3 & 0.773 & 0.676 & 0.503 \\
\hline type 4 & 0.872 & 0.807 & 0.670 \\
\hline Average & 0.761 & 0.672 & 0.560 \\
\hline \multicolumn{4}{|c|}{1997 cohort } \\
\hline type 1 & 0.502 & 0.384 & 0.238 \\
\hline type 2 & 0.656 & 0.541 & 0.371 \\
\hline type 3 & 0.672 & 0.559 & 0.388 \\
\hline type 4 & 0.798 & 0.709 & 0.549 \\
\hline Average & 0.660 & 0.549 & 0.376 \\
\hline
\end{tabular}

Table 8

The Evolution of Returns to Experience by Education Groups

\begin{tabular}{|l|c|c|c|c|}
\hline & Drop-Outs & High School & Associate & College \\
\hline 1979 Cohort & & & & \\
\hline Experience (full time) & $0.0431^{* *}$ & $0.0417^{* *}$ & $0.0459^{* *}$ & $0.1019^{* *}$ \\
\hline Experience (part time) & $0.0411^{* *}$ & $0.0445^{* *}$ & $0.0754^{* *}$ & 0.0021 \\
\hline Full-Time Job & 0.0005 & $0.0404^{* *}$ & $0.0754^{* *}$ & $0.2051^{* *}$ \\
\hline log wage error (st.dev) & $0.3333^{* *}$ & $0.3447^{* *}$ & $0.3684^{* *}$ & $0.4095^{* *}$ \\
\hline \hline 1997 cohort & & & & \\
\hline Experience (full time) & $0.0362^{* *}$ & $0.0311^{* *}$ & $0.0260^{* *}$ & $0.0650^{* *}$ \\
\hline Experience (part time) & $0.0454^{* *}$ & $0.0196^{* *}$ & $0.0406^{* *}$ & -0.0059 \\
\hline Full-Time Job & $0.1027^{* *}$ & $0.1501^{* *}$ & $0.0954^{* *}$ & $0.2170^{* *}$ \\
\hline log wage error (st.dev) & $0.3400^{* *}$ & $0.3195^{* *}$ & $0.3759^{* *}$ & $0.3898^{* *}$ \\
\hline
\end{tabular}

Note: parameters or effects with $* *$ are significant at $1 \%$ level. 
Table 9A

The Evolution of the Distribution of the College-High School and the High School Completion Premia

\begin{tabular}{|c|c|c|c|c|}
\hline & \multicolumn{2}{|c|}{ College vs High School } & \multicolumn{2}{c|}{ High School Completion } \\
\hline & $\mathbf{1 9 7 9}$ & $\mathbf{1 9 9 7}$ & $\mathbf{1 9 7 9}$ & $\mathbf{1 9 9 7}$ \\
\hline Type 1 & $37.0 \%$ & $69.5 \%$ & $17.3 \%$ & $34.2 \%$ \\
\hline Type 2 & $57.6 \%$ & $106.9 \% \%$ & $24.7 \%$ & $15.7 \%$ \\
\hline Type 3 & $36.2 \%$ & $29.7 \%$ & $21.5 \%$ & $17.3 \%$ \\
\hline Type 4 & $76.6 \%$ & $51.8 \%$ & $14.4 \%$ & $24.5 \%$ \\
\hline \hline Mean & $49.9 \%$ & $57.9 \%$ & $19.2 \%$ & $20.0 \%$ \\
\hline \hline Actual Choices & & & & \\
\hline College Graduates & $71.7 \%$ & $54.1 \%$ & - & - \\
\hline High School Graduates & - & - & $20.3 \%$ & $19.2 \%$ \\
\hline
\end{tabular}

Note: The college-high school premium and the high school completion premium are measured assuming 5 years of full-time experience.

Table 9B

The Evolution of Selectivity:

College Graduates and College Associates

\begin{tabular}{|c|c|c|c|}
\hline & \multicolumn{2}{|c|}{ Mean Log Wages } & difference (in \%) \\
\hline & Realized & Population average & \\
\hline $\mathbf{1 9 7 9}$ & & & $3 \%$ \\
\hline Associates & 2.47 & 2.44 & $8 \%$ \\
\hline College Graduates & 3.13 & 2.95 & \\
\hline & & & $-5 \%$ \\
\hline $\mathbf{1 9 9 7}$ & & & $2 \%$ \\
\hline Associates & 2.62 & 2.67 & \\
\hline college graduates & 3.05 & 3.03 & \\
\hline
\end{tabular}

Note: Mean log wages are computed at entrance in the market (with no experience) assuming a full-time job. 
Table 10

The Evolution of the Effect of Age at College Graduation on Wages at Age 28

\begin{tabular}{|c|c|c|c|c|}
\hline Dependent & \multicolumn{2}{|c|}{ log wage (79 cohort) } & \multicolumn{2}{|c|}{ log wage $(97$ cohort $)$} \\
\hline Variable & \multicolumn{2}{|c|}{$\bar{~} \overline{\text { Estimate (std. error) }}$} & \multicolumn{2}{|c|}{$\bar{~} \overline{\text { Estimate (std. error) }}$} \\
\hline Intercept & 3.954 & 4.082 & 2.845 & 3.350 \\
\hline & $(0.033)$ & $(0.014)$ & $(0.255)$ & $(0.251)$ \\
\hline Age at Graduation & -0.046 & -0.045 & -0.004 & -0.023 \\
\hline & $(0.014)$ & $(0.013)$ & $(0.010)$ & $(0.010)$ \\
\hline Type Indicators & no & yes & no & yes \\
\hline R square & 0.01 & 0.03 & 0.01 & 0.156 \\
\hline
\end{tabular}




\section{Separating Changes in Skill Prices from Com- position Effects}

As interesting as comparing estimates obtained for the 1979 and 1997 cohorts separately may be, it is not possible to separate skill price dynamics from changes in absolute quality (human capital) without imposing the restriction that the parameters of the skill production functions that govern the amount of human capital produced by schooling (with no work experience) have been stationary between the 1980's and the early 2000's. This is a crucial identification condition if one is willing to evaluate the change in average human capital level of each education group between the 1979 and the 1997 cohorts. In what follows, we now try to answer those questions.

\subsection{The Restricted Model}

We retain the same out-of-sample information about the evolution of net education cost and its related change in borrowing needs, and we re-examine the determinants of observed changes in education and labor supply after imposing the restriction that the effects of education on human capital formation (the skill formation technology) have remained constant across cohorts. To be precise, we therefore model technological changes by introducing a shift parameter to each log wage equation which measure the percent changes in skill prices taking place between the 1980's and 2000's. As before, we assume that agents making college choices in the early 2000's take those changes as exogenous. $^{21}$

Given out-of-sample information about the evolution of the net cost of higher education and its implied consequence on borrowing needs, we examine 4 potential sources explaining observed changes in individual decisions. Those are changes in skill prices (coupled with changes in wage risk), changes in the net utility of higher education as captured by changes in consumption during college, changes in grade progression standards and changes in the value of non-market time.

From now on, we draw a distinction between the parameters of the 1979 cohort (with no superscript) and those characterizing the 1997 cohort. The

\footnotetext{
${ }^{21}$ As we are modeling individual decisions only, it is reasonnable to assume that agents ignore general equilibrium issues when solving for optimal schooling and labor supply.
} 
parameterization we adopt is as follows.

Changes in skill prices and in wage risk

To capture changes in the skill price, we introduce a shift parameter to each log wage equation. We therefore obtain the following:

$$
w_{i t}^{z, 97}=\lambda^{z, 97}+\bar{w}_{i t}^{z}+\varepsilon_{i t}^{z} \text { with } z=d, h, a, c
$$

where the parameters $\lambda^{d, 97}, \lambda^{h, 97}, \lambda^{a, 97}, \lambda^{c, 95}$ are readily interpretable as percent changes in skill prices which may result from technological changes taking place between the 1980's and 2000's, or any other changes. We assume that agents making college choices in the early 2000's take those changes as exogenous.

As increase in overall wage inequality may be caused by changes in wage risk, we allow the variance of wage (log) shocks to be different between 1979 and 1997. We obtain the following expressions:

$$
\sigma_{z}(97)=\sigma_{z}+\sigma_{z}^{97} \text { with } z=d, h, a, c
$$

where $\sigma_{d}^{97}, \sigma_{h}^{97}, \sigma_{a}^{97}$ and $\sigma_{c}^{97}$ are free parameters.

Changes in grade progression standards:

For the probability of a grade increment (conditional on being enrolled), we have the following

$$
\begin{aligned}
\operatorname{Pr}\left(G_{t+1}=\right. & \left.G_{t}+1 \mid \text { in school at } t\right)^{97}= \\
& \frac{\exp \left(g_{i}+g^{97}+g_{1} \cdot I\left(12 \leq G_{i t}\right)+g_{2} \cdot d_{t s p}+g_{3} \cdot d_{t s f}\right)}{1+\exp \left(g_{i}+g^{97}+g_{1} \cdot I\left(12 \leq G_{i t}\right)+g_{2} \cdot d_{t s p}+g_{3} \cdot d_{t s f}\right)}
\end{aligned}
$$

where the parameter $g^{97}$ allows us to evaluate changes in the rate of grade advancement across cohorts, after conditioning on unobserved abilities, grade level, and labor supply during school year.

Changes in the Value of Non-Market Time

We also allow for a change in the value of non-market time as follows:

$$
\alpha_{i}^{n m}(97)=\alpha_{i}^{n m}+\alpha_{i}^{n m, 97}
$$


where the shift parameter denoted $\alpha_{i}^{n m, 97}$ measures changes in the value of non-market time.

The utility of attending higher education

To obtain the total consumption level while in college for the 1997 cohort, we write the parameters measuring the differential between the utility of high school and utility of college, $\alpha_{1 i}^{s}(97), \alpha_{1 i}^{s p}(97)$ and $\alpha_{1 i}^{s f}(97)$ as the sum of the 1979 parameters and state-specific parameters, $\alpha_{1}^{s, 97}, \alpha_{1}^{s p, 97}$ and $\alpha_{1}^{s f, 97}$, and obtain

$$
\begin{aligned}
\alpha_{1 i}^{s}(97) & =\alpha_{1 i}^{s}+\alpha_{1}^{s, 97} \\
\alpha_{1 i}^{s p}(97) & =\alpha_{1 i}^{s p}+\alpha_{1}^{s p, 97} \\
\alpha_{1 i}^{s f}(97) & =\alpha_{1 i}^{s f}+\alpha_{1}^{s f, 97}
\end{aligned}
$$

where $\alpha_{1}^{s, 97}, \alpha_{1}^{s p, 97}$ and $\alpha_{1}^{s f, 97}$ are free parameters measuring the change in net consumption after incorporating changes in tuition and borrowing needs. Given our specification, these are naturally expressed in dollars (on a per-hour basis).

However, we are agnostic about the source of those changes as they can either be interpreted as originating from parental support or from nonpecuniary dimensions. One possible interpretation is that changes in education technology, curricula or any other aspects of higher education management has changed the utility of attending education. Another one is that the non-pecuniary payoff of education attendance has changed over the 1980-2000 period. ${ }^{22}$

Conditional on the estimates obtained for the 1979 cohort, we then maximize the likelihood of wages and choices of the 1997 cohort and obtain the following vector of parameters:

$$
\left\{\alpha_{1}^{s, 97}, \alpha_{1}^{s p, 97}, \alpha_{1}^{s f, 97}, g^{97}, \lambda^{d, 97}, \lambda^{h, 97}, \lambda^{a, 97}, \lambda^{c, 97}, \sigma_{d}^{97}, \sigma_{h}^{97}, \sigma_{a}^{97}, \sigma_{c}^{97}, \alpha_{i}^{n m, 97}\right\}
$$

To implement this restriction, we need the type probabilities of the 1997 cohort to be the same as the 1979 cohort and also need to impose 16 wage intercepts of the 1997 cohort to be the same as those of the 1979 cohort.

\footnotetext{
${ }^{22}$ This would be the case if education is a luxury good (Bils and Klenow, 2000) or if social pressure to get educated has increased over this period.
} 


\subsection{Results}

The estimates found in column 1 of Table 11 provide answers to some of the questions raised earlier. To improve understanding of the model's mechanics, we estimated a specification where all observed changes are solely explained by changes in skill prices (column 1) and a version where changes are explained solely by movements in the utility of attending education (column 2). The specification that incorporates all possibilities is in column 3 .

When we assume that the only difference between the 1979 and the 1997 cohorts was skill prices, the estimates indicate that except for high school drop-outs, the skill prices of all other education groups have increased. More

precisely, the drop-out skill price dropped by about $5 \%$ while both high school and college graduate skill prices increased by $6 \%$. Interestingly, the college associates skill price is the one that has increased the most with a $9 \%$ variation.

Suppose now that we search for explanations that involve the utility of attending high education only. Not surprisingly, the estimates found in column 2 indicate that it is not possible to explain the behavior of the 1997 cohort without increases in net consumption while in college. However, this increase is far from being as large as the one observed when estimating the model for both cohorts separately. When expressed as a percentage of the 1979 cohort estimates, the changes in consumption obtained for those who do not work $(\$ 1.48)$, those who work part-time $(\$ 1.40)$ and those who work full-time (\$1.69), imply increases ranging from $29 \%$ to $39 \%$. This may be explained as follows. In the 1997 cohort, a larger number of individuals enter college and also take more time to graduate. Because the estimates of column 2 have been obtained with the grade progression rate parameters of the 1979 cohort, they make marginal entrants more likely to graduate than they would be if parameters would be freely estimated.

The most interesting estimates, found in column 3, are those obtained when searching for all possible channels since they allow us to confront various hypotheses. When doing so, we note some key differences across education groups. High school drop-outs have seen the largest reduction in skill price, with a drop of $3 \%$, while the skill price of high school graduates has increased by $3 \%$. College associates have experienced the highest skill price increase, with a $20 \%$ raise. Interestingly, the skill price of college graduates has remained practically constant. 
At the same time, the utilities of attending school have increased by more than when they were assumed to be the only sources of change, as was the case in column (2). Although this is the case for all different combinations of school attendance and work, the largest increase has been for school attendance with no work. Expressed in terms of a percentage increase in net consumption, their increase in hourly net consumption of $\$ 2.04$ translates into a $54 \%$ increase. For those in school and working part-time, the increase of $\$ 2.81$ implies a $58 \%$ increase, while the $\$ 3.36$ increase for those working full-time represents a $67 \%$ increase.

With respect to grade progression, we also note a sizeable reduction in grade advancement probability from the early 1980 's to the early 2000 's. The drop in grade progression probabilities lies between 0.14 and 0.16. Again, this is the case even after conditioning on unobserved heterogeneity. There is therefore no evidence that grade progression has become more easy. ${ }^{23}$

Finally, the value of non-market time has increased by $\$ 0.59$. This represents an increase of more than $50 \%$ for drop-outs, $30 \%$ for high school graduates, and about $25 \%$ for college associates. For college graduates (who were endowed with a value of non-market time above $\$ 4$ per hour), this represents a relatively more modest increase of around $15 \%$.

Although the increases in net consumption obtained in column 3 may be judged spectacular compared to those obtained in column 2, they may be explained by the allowance for differential grade progression probabilities. Forward looking agents, who internalize much lower grade advancement probabilities than in the early 1980's, either require higher college skill prices and/or must be endowed with a higher level of utility of attending higher education, in order to enroll in college. As post-schooling wage data do not support the hypothesis of large skill price increases for college graduates, a high increase in net consumption is required in order to rationalize observed choices.

\subsection{Changes in Absolute College Quality}

With estimates of the movements in skill prices for all education groups, it is now possible to evaluate the difference in human capital between members

\footnotetext{
${ }^{23}$ This does not imply that college admission standards have increased. Indeed, there seems to be empirical evidence that increased college enrollments are found largely among low quality colleges (Hoxby, 2009).
} 
of any given education groups across cohorts more precisely than with the unrestricted models. To obtain these estimates of absolute quality changes, we only need to simulate the restricted version of the model, and obtain the distribution of types among each education groups. While the 1997 cohort is assumed to face the same skill production function, it is exerting choices within a different environment; higher utility of attending colleges, different skill prices, lower grade progression probabilities and higher values of nonmarket time.

For each group, we report the average level of human capital at market entrance (with no experience) using the wage equation that matches simulated choices. ${ }^{24}$ Computing it requires to simulate choices of the 1997 cohort with the parameters of the restricted models. We then compute the relevant average human capital (essentially the log wages minus the log skill price) using the distribution of wage intercept terms that corresponds to the choice of each artificial individual. As the composition of types changes because the recent cohort faces different parameters, the difference in human capital is reflecting a composition effect only.

The changes in human capital (net of skill price changes) are reported in Table 12. The average human capital of both drop-outs and high school graduates appear to have remained more or less constant. While these changes are modest, the average quality of college associates has depreciated by as much as $9 \%$. This is not surprising. As already noted in the previous section, we found evidence that wages of college associates (in employment requiring some college), which were above population average in the 1980's, moved slightly below the population average in the early 2000's. At the same time, the raise in college participation may easily be explained by the increase in skill price noted in Table 11. Finally, as is the case for high school drop-outs and high school graduates, the average human capital of college graduates has been almost constant, as our estimates point to a decrease of $1 \%$ only.

To summarize, the decline in absolute college associate quality may simply reflect the increasing trend in enrollments in lower quality colleges. As the fraction of the population graduating from 4 year colleges has been much more stable than the fraction of the population that has participated in

\footnotetext{
${ }^{24}$ This means, for instance, that we are not interested in measuring quantities answering questions such as: how would the 1997 cohort of college graduates do, compared with the 1979 cohort of college graduates, if both had been employed in typical high school jobs.
} 
college, the stability of absolute college graduate quality is not surprising.

Table 11

Measuring Changes in Skill Prices

\begin{tabular}{|c|c|c|c|}
\hline & \multicolumn{3}{|c|}{1997 Cohort } \\
\hline & (1) & $(2)$ & (3) \\
\hline \multicolumn{4}{|l|}{ \$ $\$ \Delta$ in Consumption $(\%)$} \\
\hline$\alpha_{1}^{s, 97}$ (college and no work) & - & $\$ 1.48^{* *}(39 \%)$ & $\$ 2.04^{* *}(54 \%)$ \\
\hline$\alpha_{1}^{s p, 97}$ (college and part-time work) & - & $\$ 1.39^{* *}(29 \%)$ & $\$ 2.81^{* *}(58 \%)$ \\
\hline$\alpha_{1}^{s f, 97}$ (college and full-time work) & - & $\$ 1.69^{* *}(34 \%)$ & $\$ 3.36^{* *}(67 \%)$ \\
\hline \multicolumn{4}{|l|}{$\Delta$ in Grade Progression Prob. } \\
\hline College and no Work & - & & $-0.136^{* *}$ \\
\hline College and part-time work & - & & $-0.156^{* *}$ \\
\hline College and full-time work & - & & $-0.159^{* *}$ \\
\hline \multicolumn{4}{|l|}{$\Delta$ in Log Skill Prices } \\
\hline$\lambda^{d, 97}$ (drop-outs) & $-0.047^{* *}$ & - & $-0.029^{* *}$ \\
\hline$\lambda^{h, 97}$ (HS graduates) & $0.061^{* *}$ & - & $0.026^{* *}$ \\
\hline$\lambda^{a, 97}$ (Associates) & $0.094^{* *}$ & - & $0.202^{* *}$ \\
\hline$\lambda^{c, 97}$ (College Graduates) & $0.057^{* *}$ & - & -0.005 \\
\hline \multicolumn{4}{|l|}{$\Delta$ in Wage Risk } \\
\hline$\sigma_{d}^{97}$ & $0.028^{* *}$ & - & $0.0210^{* *}$ \\
\hline$\sigma_{h}^{97}$ & $0.042^{* *}$ & - & $-0.0031^{* *}$ \\
\hline$\sigma_{a}^{97}$ & $0.092^{* *}$ & - & $0.0378^{* *}$ \\
\hline$\sigma_{c}^{97}$ & $0.043^{* *}$ & - & $0.0311^{* *}$ \\
\hline \multicolumn{4}{|l|}{$\Delta$ in Non-Market Time } \\
\hline$\alpha_{i}^{n m, 97}($ in $\$)$ & - & - & $\$ 0.5942^{* *}$ \\
\hline
\end{tabular}

Note: parameters or effects with $* *$ are significant at $1 \%$ level. 
Table 12

The Evolution of Educational Selectivity: Changes in Mean Human Capital

\begin{tabular}{|c|c|c|c|}
\hline \multicolumn{4}{|c|}{$\Delta$ in Mean Human capital } \\
\hline \multicolumn{4}{|c|}{97 cohort-79 cohort (in \%) } \\
\hline \hline Drop-Outs & High School & Associates & College \\
\hline \hline $2 \%$ & $1 \%$ & $-9 \%$ & $-1 \%$ \\
\hline
\end{tabular}

Note: Human Capital is evaluated using the distribution of log wage intercepts in jobs corresponding to each simulated schooling level.

\section{Summary and Conclusion}

We have estimated a structural dynamic Roy model of education, labor supply and earnings on two cohorts of US males; one that made their college decisions in the early 1980's and another one that made it in the early 2000's. This has allowed us to evaluate to extent to which changes in i) the collegehigh school premium, ii) the utility of attending higher education, (iii) grade progression probabilities, and iv) the value of non-market time are needed to reconcile changes in education and labor supply decisions observed over this period. We have used the model to quantify the evolution of the relative and absolute qualities of both college graduates and college attendants (associates).

There are at least 4 main results to retain from our analysis. First, and foremost, changes in observed schooling decisions cannot be rationalized without appealing to a spectacular increase in intrinsic taste for education. This is true even if the total costs of college have practically doubled and borrowing levels have increased accordingly and it is the case regardless of the amount of labor supplied during college.

A second major finding is the decline in relative quality of college graduates accompanied by a stability of absolute quality. While the population average college-high school premium increased modestly, the realized college premium dropped substantially. Overall, this indicates that between 1980 and the early 2000's, the sub-population of college graduates have become gradually more representative of the population, thereby pointing to a decline in the relative quality of college graduates. 
In the 1979 cohort, there was strong positive selection characterizing college graduates, as they earned $8 \%$ more than the population average in a college job. By the early 2000, college graduates earned only $2 \%$ more than the population average and positive selection prevailing in the early 1980's had almost entirely vanished. Despite this, the average level of human capital of college graduates in the early 2000's is identical to college graduates of the 1980's and the college graduate skill price has not changed. The absolute quality of college graduates therefore seems to have remained constant.

A third finding is the decline in both relative and absolute quality of college associates. In the early 1980's, the average wage of college associates (in a college associate job) was slightly above the population average as the differential was about $3 \%$ and therefore pointed toward the existence of a weak positive selection among college associates. In the 2000 cohort, the ordering was reversed and the sub-population of college associates was earning $5 \%$ less than the population average. Positive selection was transformed into negative selection. When distinguishing between change in skill prices and changes in human capital (something feasible only when restricting the skill production functions to be stationary), we find that the average human capital level of college associates has depreciated by $9 \%$ while their skill price has increased and therefore concluded in favor of a decrease in absolute quality of college associates.

Finally, in the early 1980's, college graduates experienced much larger wage gains in the early phase of the life-cycle due to a 6 percentage points difference in returns to experience compared with high school graduates. In the 1997 cohort, age earnings profiles have flattened and the college-high school differential in returns to full-time experience has been reduced by half while the college-high school premium seems to be located at entrance in the market. The flattening of age earnings profiles has practically eliminated the negative effect of late college graduation on early life-cycle wages. Our estimates indicate that it moved from a $4 \%$ penalty per year of delay to an insignificant quantity by the early 2000's.

The results obtained in this research have been for two main cohorts of the NLSY followed from age 16 to 28. This was done in order avoid making unrealistic assumptions about how young individuals would have been capable to anticipate the 2008 recession. Since then, college attendance have continued to rise and the cost of college appears to have flattened (Dynarski and Scott-Clayton, 2013). This suggests that both average and relative col- 
lege quality of more recent cohorts (those enrolling after 2008) might have been affected and that non-standard college trajectories might have become more common. The evolution of college selectivity is far from being a closed topic.

\section{References}

[1] Abel J.R. and R. Deitz (2014) "Do the Benefits of College Still Outweigh the Costs? Current Issues in Economics and Finance, NY Federal Reserve Board, 20 (3)

[2] Abbot, B., Gallipoli, G., Meghir, C., \& Violante, G. (2013) Education decisions and intergenerational transfers in equilibrium (Working $\mathrm{Pa}$ per). New York: New York University

[3] Altonji, J., Bharadwaj P. and F. Lange (2010) "Changes in the Characteristics of American Youth: Implications for Adult Outcomes, "Journal of Labor Economics", 30,

[4] Ashworth, Jared, V. Joseph Hotz, Arnaud Maurel, and Tyler Ransom (2020), "Changes across Cohorts in Wage Returns to Schooling and Early Work Experiences", NBER Working Paper.

[5] Arcidiacono Peter, Esteban Aucejo, Arnaud Maurel and Tyler Ransom (2019) "College Attrition and the Dynamics of Information Revelation" NBER Working Paper.

[6] Autor D., L. Katz and M. Kearney (2008) "Trends in U.S. Wage Inequality: Revising the Revisionists", Review of Economics and Statistics, Vol $90,2,300-323$

[7] Babcock P. and Marks M. (2011) "The Falling Time Cost of College: Evidence from a Century of Time Use Data "The Review of Economics and Statistics", May 2011, 93(2): 468-478

[8] Belley P. and L. Lochner (2007) "The Changing Role of Family Income and Ability in Determining Educational Achievement" NBER Working Paper 13527 
[9] Beaudry, Paul, David A. Green, and Benjamin M. Sand. 2014. The declining fortunes of the young since 2000. American Economic Review 104, no. 5:381-386.

[10] Belzil, Christian (2007) "The Return to Schooling in Structural Dynamic Models: A Survey" European Economic Review, 51(5):1059-1105.

[11] Belzil, Christian, Jorgen Hansen and Xingfei Liu (2017) "Dynamic Skill Accumulation, Education Policies and the Return to Schooling", Quantitative Economics, 2017, 8 (3), 895-927 (DOI: 10.3982/QE321)

[12] Belzil, Christian and Jorgen Hansen (2002) "Unobserved Ability and the Return to Schooling", Econometrica, 70(5):2075-2091

[13] Belzil, Christian and Jorgen Hansen (2020) "The Evolution of the US Family Income-Schooling Relationship and Educational Selectivity" forthcoming in Journal of Applied Econometrics

[14] Bils, Mark and Peter .J. Klenow (2000), Does Schooling Cause Growth?, American Economic Review, 90, 1160-1183

[15] Bowlus, Audra J., and Chris Robinson. 2012 "Human Capital Prices, Productivity, and Growth.", American Economic Review, 102(7): 34833515 .

[16] Bound, John, Michael F. Lovenheim, and Sarah Turner (2012) "Increasing time to baccalaureate degree in the United States", Education Finance and Policy 7, no. 4:375-424.

[17] Card D. and T. Lemieux (2001) "Can Falling Supply can Explain the Rising Return to College for Younger Men" Quarterly Journal of Economics 116 (May), 705-746.

[18] Carneiro, Pedro and Sokbae Lee. 2011. Trends in quality-adjusted skill premia in the united states, 1960-2000. American Economic Review 101, no. 6:2309-2349.

[19] Castro, Rui and Daniele Coen-Pirani "Explaining the Evolution of Educational Attainment in the United States $\dagger$, American Economic Journal: Macroeconomics 2016, 8(3): 77-112 
[20] Cunha F. and J.J. Heckman (2007) "The Evolution of Inequality, Heterogeneity and Uncertainty in Labor Earnings in the U.S. Economy" IZA DP No. 3115

[21] Cunha, Flavio, Fatih Karahan, and Ilton Soares. 2011 "Returns to skills and the college premium" Journal of Money, Credit and Banking 43, no. 5:39-86.

[22] Castex, G. and E. Dechter (2014) "The Changing Role of Education and Ability in Wage Determination" Journal of Labor Economics",Vol. 32, No. 4, pp. $685-710$

[23] Deming, David J. 2017. The growing importance of social skills in the labor market. Quarterly Journal of Economics 132, no. 4:1593-1640.

[24] Dynarski, Susan M. and Judith Scott-Clayton (2016), Financial Aid Policy: Lessons from Research, Future of Children, 23, 67-91.

[25] Eckstein, Zvi and Kenneth I. Wolpin (1999) "Why Youths Drop Out of High School: The Impact of Preferences, Opportunities, and Abilities" Econometrica, Vol. 67, No. 6, pp. 1295-1339

[26] Eisenhauer, P., J.J. Heckman and E. Vytlacil (2015) "The Generalized Roy Model and the Cost-Benefit Analysis of Social Programs" Journal of Political Economy, 123(2): 413-443.

[27] Fortin, Nicole M. 2006. Higher-education policies and the college wage premium: Cross-state evidence from the 1990s. American Economic Review 96, no. 4:959-987.

[28] Gemici A. and Matthew Wiswall (2014) "Evolution of Gender Differences in Post-Secondary Human Capital Investments: College Majors", International Economic Review, 55(1),

[29] Gong Y, L. Lochner, T. Stinebrickner, and R. Stinebrickner (2019) "The Consumption Value of College", Working Paper, University of Western Ontario

[30] Heckman, J. J. (2010) "Building Bridges Between Structural and Program Evaluation Approaches to Evaluating Policy" Journal of Economic Literature, 48 (2), 356-398. 
[31] Heckman, J. J., Lochner, L. and C. Taber (1998) "Explaining Rising Wage Inequality: Explorations with a Dynamic General Equilibrium Model of Labor Earnings With Heterogeneous Agents" Review of Economic Dynamics, 1 (1), 1-58.

[32] Heckman, J.J. and T. Kautz (2014) "Achievements Tests and the Role of Character in American Life" in The Myth of Achievement Tests: The GED and the Role of Character in American Life, Chapter 1, 3-56, University of Chicago Press.

[33] Jacob, B., B. McCall, and K. Stange (2018) "College as Country Club: Do Colleges Cater to Students Preferences for Consumption? Journal of Labor Economics, 36(2):309\{348, 2018.

[34] Johnson, M.T. "Borrowing Constraints, College Enrollment, and Delayed Entry" Journal of Labor Economics, 2013, vol. 31, no. 4]

[35] Juhn, C., K.M. Murphy and B. Pierce (1993) "Wage Inequality and the Rise in Returns to Skill", Journal of Political Economy, 101 (3), 410-442.

[36] Jeong, Hyeok, Yong Kim, and Iourii Manovskii, "The price of experience," The American Economic Review, 2015, 105 (2), 784-815.29

[37] Kambourov, G. and Manovskii, I. (2009) "Occupational Mobility and Wage Inequality", Review of Economic Studies 76(2), 732-59.

[38] Keane, Michael P. and Kenneth I. Wolpin (1997), The Career Decisions of Young Men, Journal of Political Economy, 105, 473-522.

[39] Kong, Y.-C. \& Ravikumar, B. \& Vandenbroucke, G., 2018. "Explaining cross-cohort differences in life-cycle earnings," European Economic Review, Elsevier, vol. 107(C), pages 157-184.

[40] Lee, D. and K.I. Wolpin (2010) "Accounting for Wage and Employment Changes in the US from 1968-2000: A Dynamic Model of Labor Market Equilibrium" Journal of Econometrics, 156: 68-85

[41] Scott-Clayton, Judith. 2012. What explains trends in labor supply among US undergraduates? National Tax Journal 65, no. 1:181-210. 
[42] Sullivan, Paul (2006) "Interpolating Value Functions in Discrete Choice Dynamic Programming Models", Working Paper, University of Munich

[43] Sullivan, Paul (2010) "A Dynamic Analysis Of Educational Attainment, Occupational Choices, And Job Search," International Economic Review, vol. 51(1), pages 289-317.

[44] Todd, P. E and W. Zhang (2019) "A Dynamic Model of Personality, Schooling, and Occupational Choice", forthcoming in Quantitative Economics

[45] Valletta, Robert G. (2016) Recent Flattening in the higher education wage premium: Polarization, skill downgrading, or both? Federal Reserve Bank of San-Francisco, Working Paper 2016-17 
Table A1: Details on Sample selections

Remaining individuals after:

Selecting cross-section and individuals between 14 and 17 in 1979 or 1997

Keeping males only

Removing those with initial grade (at age 16) $<8$

Removing those with initial grade (at age 16) $>12$

Removing those with no information after age 20

Removing those with missing information on AFQT
NLSY 1979

NLSY 1997

5,405

1,491

2,752

1,475

2,727

1,474

2,723

1,320

2,626

1,294 
Table A2: Average hourly wages by education

Educational attainment

High school dropout

High school graduate

Associate college

College graduate
NLSY 1979

NLSY 1997

11.7

12.7

12.8

13.5

14.1

17.9 
Table A3: Proportion of sample in education and work, by age.

NLSY 1979

\begin{tabular}{ccccccccc}
\cline { 3 - 8 } Period & Age & N & No work & PT work & FT work & PT work & FT work & No work \\
\cline { 3 - 8 } & 16 & 1294 & 0.340 & 0.523 & 0.045 & 0.032 & 0.026 & 0.034 \\
2 & 17 & 1294 & 0.290 & 0.361 & 0.065 & 0.095 & 0.113 & 0.077 \\
3 & 18 & 1294 & 0.143 & 0.247 & 0.043 & 0.156 & 0.262 & 0.150 \\
4 & 19 & 1294 & 0.116 & 0.202 & 0.047 & 0.153 & 0.336 & 0.146 \\
5 & 20 & 1294 & 0.107 & 0.166 & 0.048 & 0.144 & 0.401 & 0.134 \\
6 & 21 & 1294 & 0.085 & 0.121 & 0.044 & 0.149 & 0.479 & 0.121 \\
7 & 22 & 1244 & 0.046 & 0.069 & 0.048 & 0.134 & 0.587 & 0.116 \\
8 & 23 & 1204 & 0.028 & 0.038 & 0.049 & 0.117 & 0.669 & 0.098 \\
9 & 24 & 1169 & 0.020 & 0.023 & 0.056 & 0.109 & 0.711 & 0.080 \\
10 & 25 & 976 & 0.022 & 0.012 & 0.052 & 0.086 & 0.747 & 0.081 \\
11 & 26 & 661 & 0.008 & 0.023 & 0.056 & 0.083 & 0.753 & 0.077 \\
12 & 27 & 351 & 0.011 & 0.026 & 0.046 & 0.088 & 0.755 & 0.074 \\
13 & 28 & 85 & 0.000 & 0.000 & 0.047 & 0.059 & 0.812 & 0.082 \\
\hline
\end{tabular}

NLSY 1997

\begin{tabular}{ccccccccc}
\cline { 3 - 8 } Period & Age & \multicolumn{3}{c}{ School } & \multicolumn{3}{c}{ No school } \\
\cline { 3 - 8 } & 16 & 2069 & 0.247 & 0.663 & 0.035 & 0.019 & 0.008 & 0.028 \\
2 & 17 & 2069 & 0.314 & 0.449 & 0.098 & 0.040 & 0.033 & 0.066 \\
3 & 18 & 2069 & 0.217 & 0.304 & 0.093 & 0.121 & 0.158 & 0.108 \\
4 & 19 & 2069 & 0.136 & 0.198 & 0.069 & 0.162 & 0.271 & 0.164 \\
5 & 20 & 2069 & 0.110 & 0.170 & 0.072 & 0.141 & 0.327 & 0.179 \\
6 & 21 & 2069 & 0.118 & 0.137 & 0.066 & 0.141 & 0.348 & 0.190 \\
7 & 22 & 2050 & 0.084 & 0.097 & 0.063 & 0.129 & 0.437 & 0.190 \\
8 & 23 & 2033 & 0.051 & 0.051 & 0.055 & 0.143 & 0.522 & 0.178 \\
9 & 24 & 2014 & 0.040 & 0.039 & 0.040 & 0.128 & 0.572 & 0.182 \\
10 & 25 & 1990 & 0.027 & 0.040 & 0.040 & 0.108 & 0.586 & 0.199 \\
11 & 26 & 1432 & 0.020 & 0.020 & 0.051 & 0.121 & 0.574 & 0.214 \\
12 & 27 & 901 & 0.017 & 0.022 & 0.050 & 0.103 & 0.597 & 0.211 \\
13 & 28 & 414 & 0.019 & 0.010 & 0.051 & 0.116 & 0.582 & 0.222 \\
\hline \hline
\end{tabular}




\section{Table A4: Debt load and repayments}

\begin{tabular}{lccccc} 
Variable & Obs & Mean & Std. Dev. & Min & Max \\
\hline Repayments & & & 1979 & & \\
\hline Overall & 13,454 & 0.111 & 0.259 & 0.000 & 2.175 \\
Fraction with positive amount & 13,454 & 0.216 & 0.412 & 0.000 & 1.000 \\
$\quad$ Amount conditional on being positive & 2,908 & 0.515 & 0.321 & 0.136 & 2.175 \\
Debt load & & & & & \\
$\quad$ Overall & 13,454 & 0.746 & 1.738 & 0.000 & 14.592 \\
Fraction with positive amount & 13,454 & 0.216 & 0.412 & 0.000 & 1.000 \\
Amount conditional on being positive & 2,908 & 3.453 & 2.151 & 0.912 & 14.592 \\
& & & & & \\
Repayments & & & 1997 & & \\
\hline Overall & 23,248 & 0.230 & 0.510 & 0.000 & 4.332 \\
$\quad$ Fraction with positive amount & 23,248 & 0.251 & 0.434 & 0.000 & 1.000 \\
$\quad$ Amount conditional on being positive & 5,846 & 0.916 & 0.636 & 0.228 & 4.332 \\
Debt load & & & & & \\
$\quad$ Overall & 23,248 & 1.779 & 3.937 & 0.000 & 33.450 \\
Fraction with positive amount & 23,248 & 0.251 & 0.434 & 0.000 & 1.000 \\
Amount conditional on being positive & 5,846 & 7.076 & 4.914 & 1.761 & 33.450 \\
\hline
\end{tabular}


Table A5: Structural Estimates

\begin{tabular}{|c|c|c|c|c|c|c|}
\hline \multirow[b]{2}{*}{ Parameter } & \multicolumn{3}{|c|}{1979 cohort } & \multicolumn{3}{|c|}{1997 cohort } \\
\hline & Estimate & std. err. & T-statistic & Estimate & std. err. & T-statistic \\
\hline \multicolumn{7}{|c|}{ Utility of study and no work } \\
\hline aOs & 3.240 & 0.170 & 19.08 & 2.683 & 0.146 & 18.33 \\
\hline a1s - type 2 & -0.582 & 0.263 & -2.22 & -0.937 & 0.216 & -4.33 \\
\hline a1s - type 3 & -2.646 & 0.194 & -13.63 & -1.801 & 0.138 & -13.07 \\
\hline a1s - type 4 & 9.180 & 0.976 & 9.41 & -0.017 & 0.091 & -0.19 \\
\hline a2s & 0.470 & 0.219 & 2.14 & 11.851 & 0.783 & 15.13 \\
\hline \multicolumn{7}{|c|}{ Utility of study and part-time work } \\
\hline a0sp & -2.271 & 0.097 & -23.42 & -2.799 & 0.073 & -38.48 \\
\hline a1sp - type 2 & -1.475 & 0.139 & -10.65 & 1.398 & 0.154 & 9.10 \\
\hline a1sp - type 3 & -0.483 & 0.112 & -4.32 & 1.308 & 0.130 & 10.06 \\
\hline a1sp - type 4 & 4.082 & 0.492 & 8.30 & 1.878 & 0.199 & 9.46 \\
\hline $\mathrm{a} 2 \mathrm{sp}$ & 1.137 & 0.211 & 5.40 & 8.756 & 0.631 & 13.88 \\
\hline \multicolumn{7}{|c|}{ Utility of study and full-time work } \\
\hline a0sf & -7.997 & 0.125 & -63.96 & -8.374 & 0.143 & -58.52 \\
\hline a1sf - type 2 & -0.554 & 0.160 & -3.45 & 2.169 & 0.214 & 10.12 \\
\hline a1sf - type 3 & 0.073 & 0.125 & 0.59 & 2.094 & 0.215 & 9.74 \\
\hline a1sf - type 4 & -0.008 & 0.232 & -0.04 & 0.492 & 0.227 & 2.17 \\
\hline a2sf & 1.078 & 0.208 & 5.18 & 3.653 & 0.480 & 7.61 \\
\hline \multicolumn{7}{|c|}{ Utility of full-time work } \\
\hline af - type 1 & 1.415 & 0.064 & 22.15 & 1.145 & 0.079 & 14.41 \\
\hline af - type 2 & -1.069 & 0.079 & -13.53 & -1.580 & 0.083 & -19.03 \\
\hline af - type 3 & -0.116 & 0.064 & -1.81 & 0.312 & 0.055 & 5.70 \\
\hline af - type 4 & -2.355 & 0.098 & -24.12 & -2.586 & 0.104 & -24.84 \\
\hline afh & 0.943 & 0.029 & 32.26 & 0.786 & 0.029 & 27.56 \\
\hline afa & 1.537 & 0.051 & 30.28 & 1.879 & 0.053 & 35.56 \\
\hline afc & 3.556 & 0.079 & 45.20 & 3.265 & 0.075 & 43.36 \\
\hline \multicolumn{7}{|c|}{ Utility of non-market time } \\
\hline anm - type 1 & 0.938 & 0.046 & 20.29 & 2.161 & 0.153 & 14.11 \\
\hline anm - type 2 & 2.791 & 0.063 & 44.05 & 2.824 & 0.047 & 59.75 \\
\hline anm - type 3 & 0.560 & 0.095 & 5.92 & 0.830 & 0.081 & 10.22 \\
\hline anm - type 4 & -1.926 & 0.131 & -14.76 & -0.637 & 0.156 & -4.08 \\
\hline anmh & 0.523 & 0.043 & 12.24 & 0.502 & 0.030 & 16.48 \\
\hline anma & 0.990 & 0.072 & 13.72 & 1.065 & 0.074 & 14.39 \\
\hline anmc & 3.358 & 0.125 & 26.85 & 1.675 & 0.120 & 13.95 \\
\hline \multicolumn{7}{|c|}{ Wages - high school dropouts } \\
\hline Id - type 1 & 2.222 & 0.015 & 149.32 & 2.376 & 0.019 & 124.41 \\
\hline Id - type 2 & 2.084 & 0.014 & 148.43 & 2.050 & 0.011 & 181.98 \\
\hline Id - type 3 & 1.895 & 0.019 & 100.62 & 2.053 & 0.011 & 187.97 \\
\hline Id - type 4 & 2.043 & 0.018 & 116.34 & 1.959 & 0.020 & 97.48 \\
\hline Idf & 0.073 & 0.003 & 22.30 & 0.036 & 0.003 & 11.75 \\
\hline Idp & 0.071 & 0.006 & 12.28 & 0.045 & 0.005 & 10.06 \\
\hline Ids & 0.001 & 0.015 & 0.03 & 0.103 & 0.014 & 7.45 \\
\hline sigma_d & 0.333 & 0.006 & 59.34 & 0.340 & 0.005 & 74.48 \\
\hline
\end{tabular}




\begin{tabular}{|c|c|c|c|c|c|c|}
\hline \multirow{2}{*}{$\begin{array}{l}\text { Table A5: continued } \\
\text { Wages - high school graduates }\end{array}$} & \multicolumn{3}{|c|}{1979 cohort } & \multicolumn{3}{|c|}{1997 cohort } \\
\hline & Estimate & std. err. & T-statistic & Estimate & std. err. & T-statistic \\
\hline Ih - type 1 & 2.355 & 0.014 & 174.04 & 2.669 & 0.024 & 112.49 \\
\hline lh - type 2 & 2.322 & 0.013 & 182.44 & 2.157 & 0.015 & 148.19 \\
\hline Ih - type 3 & 2.070 & 0.014 & 150.25 & 2.176 & 0.013 & 172.97 \\
\hline Ih - type 4 & 2.147 & 0.020 & 105.31 & 2.134 & 0.018 & 116.47 \\
\hline Ihf & 0.042 & 0.002 & 19.51 & 0.031 & 0.003 & 11.02 \\
\hline Ihp & 0.045 & 0.003 & 15.14 & 0.020 & 0.004 & 5.18 \\
\hline Ihs & 0.040 & 0.012 & 3.41 & 0.150 & 0.012 & 12.89 \\
\hline sigma_h & 0.345 & 0.004 & 87.64 & 0.320 & 0.003 & 92.96 \\
\hline \multicolumn{7}{|l|}{ Wages - associate college } \\
\hline la - type 1 & 2.377 & 0.034 & 70.10 & 3.284 & 0.076 & 43.22 \\
\hline la - type 2 & 2.107 & 0.033 & 63.26 & 2.344 & 0.033 & 71.55 \\
\hline la - type 3 & 1.890 & 0.038 & 49.66 & 2.381 & 0.026 & 92.26 \\
\hline la - type 4 & 2.049 & 0.026 & 80.02 & 2.160 & 0.021 & 103.28 \\
\hline laf & 0.046 & 0.006 & 7.82 & 0.026 & 0.005 & 5.35 \\
\hline lap & 0.089 & 0.007 & 12.98 & 0.041 & 0.006 & 6.76 \\
\hline las & 0.075 & 0.024 & 3.11 & 0.095 & 0.019 & 5.15 \\
\hline sigma_a & 0.368 & 0.009 & 41.65 & 0.376 & 0.007 & 53.65 \\
\hline \multicolumn{7}{|l|}{ Wages - college graduates } \\
\hline Ic - type 1 & 2.266 & 0.062 & 36.37 & 3.124 & 0.094 & 33.11 \\
\hline Ic - type 2 & 2.427 & 0.183 & 13.27 & 2.988 & 0.037 & 81.80 \\
\hline lc - type 3 & 1.973 & 0.086 & 22.87 & 2.233 & 0.046 & 48.72 \\
\hline lc - type 4 & 2.453 & 0.031 & 79.84 & 2.412 & 0.024 & 99.91 \\
\hline Icf & 0.102 & 0.007 & 14.61 & 0.065 & 0.006 & 11.88 \\
\hline Icp & 0.002 & 0.006 & 0.34 & -0.006 & 0.005 & -1.10 \\
\hline Ics & 0.205 & 0.029 & 6.97 & 0.217 & 0.019 & 11.28 \\
\hline sigma_c & 0.410 & 0.009 & 45.54 & 0.390 & 0.009 & 45.41 \\
\hline \multicolumn{7}{|l|}{ Grade transitions } \\
\hline g - type 1 & 2.603 & 0.090 & 28.88 & 0.710 & 0.118 & 6.04 \\
\hline g - type 2 & 1.735 & 0.104 & 16.73 & 1.347 & 0.059 & 22.71 \\
\hline g - type 3 & 2.395 & 0.112 & 21.48 & 1.418 & 0.052 & 27.08 \\
\hline g - type 4 & 3.089 & 0.100 & 30.94 & 2.073 & 0.065 & 31.91 \\
\hline g1 & -1.167 & 0.086 & -13.56 & -0.701 & 0.049 & -14.27 \\
\hline g2 & -0.493 & 0.069 & -7.11 & -0.482 & 0.046 & -10.41 \\
\hline g3 & -1.214 & 0.074 & -16.32 & -1.175 & 0.056 & -21.00 \\
\hline \multicolumn{7}{|l|}{ Type probabilities } \\
\hline p1 & 0.545 & 0.210 & 2.60 & 3.145 & 0.388 & 8.10 \\
\hline p1 - initial grade & 0.078 & 0.021 & 3.67 & -0.311 & 0.039 & -7.94 \\
\hline p1 - afqt & -1.780 & 0.112 & -15.84 & -1.538 & 0.122 & -12.58 \\
\hline p2 & 2.256 & 0.315 & 7.15 & 4.485 & 0.560 & 8.01 \\
\hline p2 - initial grade & -0.152 & 0.032 & -4.78 & -0.348 & 0.055 & -6.37 \\
\hline p2 - afqt & -2.075 & 0.124 & -16.71 & -1.403 & 0.113 & -12.48 \\
\hline p3 & 0.605 & 0.159 & 3.81 & 3.047 & 0.523 & 5.83 \\
\hline p3 - initial grade & 0.041 & 0.018 & 2.32 & -0.167 & 0.050 & -3.31 \\
\hline p3 - afqt & -2.129 & 0.121 & -17.56 & -1.415 & 0.107 & -13.28 \\
\hline
\end{tabular}

